\title{
Computational fluid dynamics analysis of top compression ring in mixed lubrication
}

\author{
Anastasios Zavos and Pantelis G. Nikolakopoulos ${ }^{\mathrm{a}}$ \\ Machine Design Laboratory, Dept. of Mechanical Engineering and Aeronautics, University of Patras, 26504 Patras, Greece
}

Received 8 September 2015, Accepted 17 March 2016

\begin{abstract}
The top compression ring design of an internal combustion engine has an impact on ring inplane motion and its lubrication conditions at the ring-cylinder liner contact. In this paper, the geometrical dimensions of the top compression piston ring-cylinder system were obtained from an actual four-stroke motorbike engine. The top ring tribological behaviour was characterized by a Computational Fluid Dynamics (CFD) simulation including the effects of asperity contact. Based on the numerical solution of the Navier-Stokes equations and taking into account realistic engine running conditions, the effect of the in-plane top ring motion in quasi-static equilibrium was determined. The simulation model was validated by the numerical and experimental results of similar investigations of other researchers. Good predictions were achieved by solving the Navier-Stokes equations because the pressure gradient into the lubricant film was accounted for. The effects of ring curvature at the ends of the stroke were studied. The results show that a flatter ring profile has a sufficient minimum lubricant thickness at reversal points, showing reasonably lower boundary friction than that of the higher curvature. Higher heights of the curvature profile promote significantly mixed lubrication, in which the power losses and the burning of excess lubricating oil are increased. The proposed simulation model can be expanded to any set of compression rings where a minimum simulation time is required.
\end{abstract}

Key words: Engines / compression rings / mixed lubrication / Navier-Stokes equations / boundary friction / power losses

\section{Introduction}

A desirable top compression ring profile could lead to good sealing performance with low frictional power loss and better oil consumption. The top compression ring is exposed to rapidly change loads due to its high pressure and low speed, and there is a need to improve its profile design. At the ends of the piston stroke (low sliding speed), there is a greater chance of asperities contact. Hence, there is a need to optimize the surface ring geometry for improved lubrication conditions at these low speed regions.

The top compression ring contribution to ring pack performance has increased from $13 \%$ in the 1980 s to $27 \%$ recently [1]. Priest et al. [2,3] combined the numerical and experimental results for measured compression ring profiles and found that a $10 \%$ reduction in mechanical losses decreases fuel consumption almost 1.5\% [2]. In addition, a detailed study showed the wear effects on the piston ring pack and was validated with experimental results in a diesel engine [3]. These studies showed that the correlation between the wear and the lubrication condi-

\footnotetext{
${ }^{a}$ Corresponding author: pnikolak@mech.upatras.gr
}

tions to ring pack is directly related to the engine life. To this end, the friction force and the minimum lubricant thickness in top piston rings attracted the attention of many researchers due to their importance during the operation of the internal combustion engines. Based on the Reynolds equation, the effect of piston ring curvature for two types of piston rings and the variation of the minimum oil thickness were described by Jeng $[4,5]$. They analysed starved and fully flooded conditions at the ringcylinder interface. Dellis [6] investigated the friction force with the use of a single ring test-rig, including the lubricant properties, the film thickness and the piston ring shape. A flatter ring shape had a lower friction at reversal points than that with higher curvature. In this direction, Taylor [7] presented a numerical analysis of the squeeze lubrication effects in piston rings. The lower viscosity oils together with the flatter ring profile can improve the lubrication conditions at reversal points. At the same time, it was concluded that the ring profile was fully covered with oil film due to 'squeeze' film effects; thus, the cavitation effects vanished at the reversals. Akalin et al. [8] studied the tribological behaviour of the piston ring using the Reynolds equation with asperity contact approach. Similarly top piston ring-cylinder contact in the mixed 


\section{Nomenclature}

\begin{tabular}{|c|c|}
\hline$A$ & Apparent smooth compression ring surface interfaced the cylinder \\
\hline$A_{\text {cont }}$ & Asperities contact area \\
\hline$B$ & Compression ring thickness \\
\hline$C$ & Compression ring curvature height \\
\hline$d_{\text {gap }}$ & Piston - piston ring end gap \\
\hline$D_{\text {cyl }}$ & Nominal cylinder diameter \\
\hline$E^{\prime}$ & Effective Young modulus of elasticity of the examined tribo pair \\
\hline$E_{\mathrm{r}}, E_{\mathrm{cyl}}$ & Young modulus of elasticity for the compression ring and the cylinder \\
\hline$F_{\text {total }}$ & Total friction force \\
\hline$F_{\mathrm{fl}}$ & Fluid friction force \\
\hline$F_{\mathrm{b}}$ & Boundary friction force \\
\hline$F_{5 / 2}, F_{2}$ & Statistical functions from Greenwood and Tripp approach \\
\hline$h_{\min }$ & Minimum lubricant thickness \\
\hline$h$ & Lubricant film thickness \\
\hline$I_{\mathrm{r}}$ & Second moment of inertia of the compression ring cross section \\
\hline$l_{\text {rod }}$ & Rod length \\
\hline$N$ & Parameter for minimum film thickness iterative process \\
\hline$p$ & Pressure \\
\hline$p_{\text {hyd }}$ & Local hydrodynamic pressure \\
\hline$p_{\mathrm{el}}$ & Elastic pressure \\
\hline$p_{\mathrm{bk}}$ & Back gas pressure \\
\hline$p_{\mathrm{c}}$ & Combustion pressure \\
\hline$p_{\text {cont }}$ & Contact pressure \\
\hline$p_{\text {in }}$ & Inlet pressure \\
\hline$p_{\text {out }}$ & Outlet pressure \\
\hline$p_{\mathrm{a}}$ & Atmospheric pressure \\
\hline$P_{\text {tot }}$ & Total power losses \\
\hline$r$ & Crank radius \\
\hline$T_{\mathrm{av}}$ & Average cylinder liner temperature \\
\hline$T_{0}$ & Ambient lubricant temperature \\
\hline$U_{\mathrm{p}}$ & Piston speed \\
\hline$W$ & Compression ring width \\
\hline$W_{\text {cont }}$ & Asperities contact load \\
\hline$X$ & Parameter for load balance criterion \\
\hline \multicolumn{2}{|r|}{ Greek symbols } \\
\hline$a_{0}, \beta_{0}$ & Atmospheric viscosity-pressure coefficients \\
\hline$\delta_{\mathrm{r}}, \delta_{\mathrm{cyl}}$ & Roughness amplitude for top ring and cylinder liner \\
\hline$\varepsilon$ & Parameter for load equilibrium \\
\hline$\zeta$ & Asperity density per unit contact area \\
\hline$\kappa$ & Average asperity tip radius \\
\hline$\lambda$ & Stribeck oil film parameter \\
\hline$\lambda_{\mathrm{CR}}$ & Control ratio \\
\hline$\mu$ & Lubricant dynamic viscosity \\
\hline$\mu_{\text {asp }}$ & Coefficient parameter of boundary shear strength \\
\hline$\mu_{0}$ & Oil dynamic viscosity at atmospheric pressure and ambient temperature \\
\hline$\nu_{\mathrm{r}}, \nu_{\mathrm{cyl}}$ & Poisson's ratio of compression ring and cylinder \\
\hline$\rho$ & Lubricant density \\
\hline$\rho_{0}$ & Lubricant density at atmospheric pressure and ambient temperature \\
\hline$\sigma_{\mathrm{r}}, \sigma_{\mathrm{cyl}}$ & Roughness parameter of compression ring and cylinder liner \\
\hline$\sigma_{\mathrm{rms}}$ & Root mean square roughness of examined tribo pair \\
\hline$\overline{\bar{\tau}}$ & Stress tensor \\
\hline$\tau$ & Viscous shear stress of the lubricant film \\
\hline$\tau_{o}$ & Eyring shear stress of the lubricant film \\
\hline$\varphi$ & Crank angle \\
\hline$\Omega$ & Rotational crankshaft speed \\
\hline$\Omega_{\text {idle }}$ & Idle rotational crankshaft speed \\
\hline$\Omega_{\max }$ & Maximum rotational crankshaft speed \\
\hline
\end{tabular}


lubrication regime was proposed by Mishra et al. [9,10]. A transient analysis has been developed for a real motorbike engine considering the ring-cylinder bore conformability and the ring deformation. In references $[9,10]$, the total friction force, the minimum oil film and the power losses were evaluated. The numerical predictions were in a good conformance with the experimental results regarding the friction force measurements by Furuhama and Sasaki [11]. In the case described by Furuhama and Sasaki, which addresses motored engine conditions, the complex ring dynamic behaviour may account for the maximum deviation between the experimental measurements [11] and the computed results [9]. Morris et al. [12,13] presented a model of top piston ring operation in the mixed hydrodynamic regime. They combined the Reynolds equation and the average flow model of Patir and Cheng [14]. In reference [12], they provided a solution for the isothermal mixed hydrodynamic conjunction of the compression ring to cylinder liner, and they also investigated the effects of the compression ring axial profile along its face-width and topography of contiguous solids. Another important feature of their analysis was the development of a control volume thermal mixing model [13], showing that the temperature of the liner is the determining factor for lubricant temperature in the contact. They also studied the lubrication conditions of new and worn compression rings to predict the friction behaviour. Styles et al. [15] studied a boundary and mixed lubrication model by considering the coating surface effects in detail. Their analysis took into account the friction of the top compression ring of a high-performance V12 Aston Martin engine. Top ring surface parameters were investigated for several engine running conditions and showed that the material properties of the coatings have a major contribution to boundary friction. Simultaneously, a mixed hydrodynamic study of the piston ring pack considering the elastoplastic contact was established by Guo et al. [16]. The general theory of contact between two rough plane surfaces by Greenwood and Tripp [17] was considered. They found that the load and the area of contact remain almost proportional, independently of the detailed mechanical and geometrical properties of the asperities. Moreover, Sonthalia et al. [18] developed a dynamic model for the mechanism of ringliner lubrication to determine the ring twist and the oil film variation. In this work, the profile of the first compression ring was analysed and designed from the tribological point of view, and the results were validated experimentally. They found that the piston ring performance was greatly affected by the curvature shape. Another example of numerical models could be found in the paper by $\mathrm{Hu}$ et al. [19]. They demonstrated a non-axisymmetrical analysis for a single piston ring in mixed lubrication. Using gas pressure, the lubrication starvation prediction of friction and oil film thickness in the circumferential direction of the ring were attained by including the asperities contact.

An analytical and experimental study regarding piston ring tribological characteristics was conducted by Hamatake et al. [20]. Their analytical model was based on the Reynolds equation, and the experimental results were derived from a four-stroke diesel engine. The authors also examined the influence of the number of rings on the engine performance. With the minimum number of rings, the friction losses decreased, as observed from their experimental results.

Generally, computational fluid dynamic (CFD) analysis offers flexibility to modify design parameters and to associate complex conditions to flow and structural studies. Shahmohamadi et al. [21, 22] proposed a novel thermomixed model combining the Navier-Stokes and RayleighPlesset equations. The contribution of asperity contact in thin lubricant films was illustrated taking into account the asperity contact model [17]. In addition to the modelling details, the volume fraction of cavitation was also obtained for the response of the piston ring sliding motion. Simulation models of top piston ring-cylinder system were presented by Zavos and Nikolakopoulos [23-25]. In their investigation [23], the mechanism of friction on a top smooth and wavy piston ring was analysed in full-flooded conditions using the Navier Stokes equations. The oil film thickness and the mechanical stresses on the piston ring were compared and discussed. In the experiment, the effect of lubricant oil was examined under cold-start engine conditions using the same rotational speed. The strain gauge method was used for the friction force measurement [24]. Comparisons between the experimental and numerical friction force were depicted and discussed. In addition to this topic, a fluid structural algorithm was solved for the hydrodynamic regime with the consideration of power law lubricants, through viscous shear of the lubricant, in a smooth and textured ring [25]. In particular, it was shown that the pseudo-plasticity effect plays a vital role in ring-bore conjunction, thus reducing the viscous friction forces.

In the present work, a 2D axisymmetric CFD model is developed to study the performance of top compression piston rings in mixed lubrication conditions. Flow simulations are performed solving the Navier-Stokes equations. The geometric dimensions of the compression ringcylinder model were obtained from an actual four-stroke motorbike engine. Realistic engine boundary conditions were applied to simulate radial ring motion in the quasistatic equilibrium region. The results of this numerical analysis showed good agreement with the results published in the literature. Further, the study places emphasis on the investigation of the top ring curvature profile in connection with the lubricant oil conditions. Thus, the proposed computational model is used to predict the total friction force, the pressure field and the minimum lubricant thickness for each top ring profile. The variation in frictional power loss with compression ring profile is also investigated.

\section{Problem definition}

In this work, the simulation is performed with a barrelfaced compression ring and a cylinder surface model of a 107 cc four-stroke motorbike gasoline engine. The asperity 

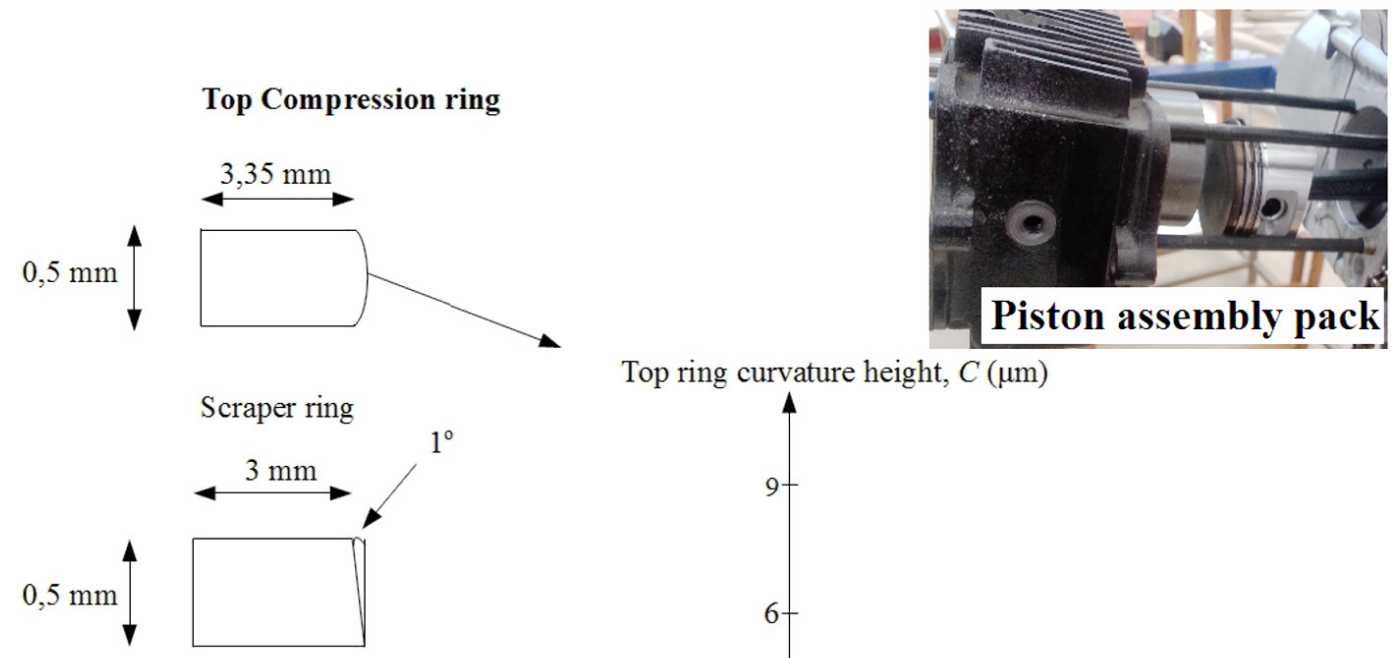

Top ring curvature height, $C(\mu \mathrm{m})$

Oil control ring
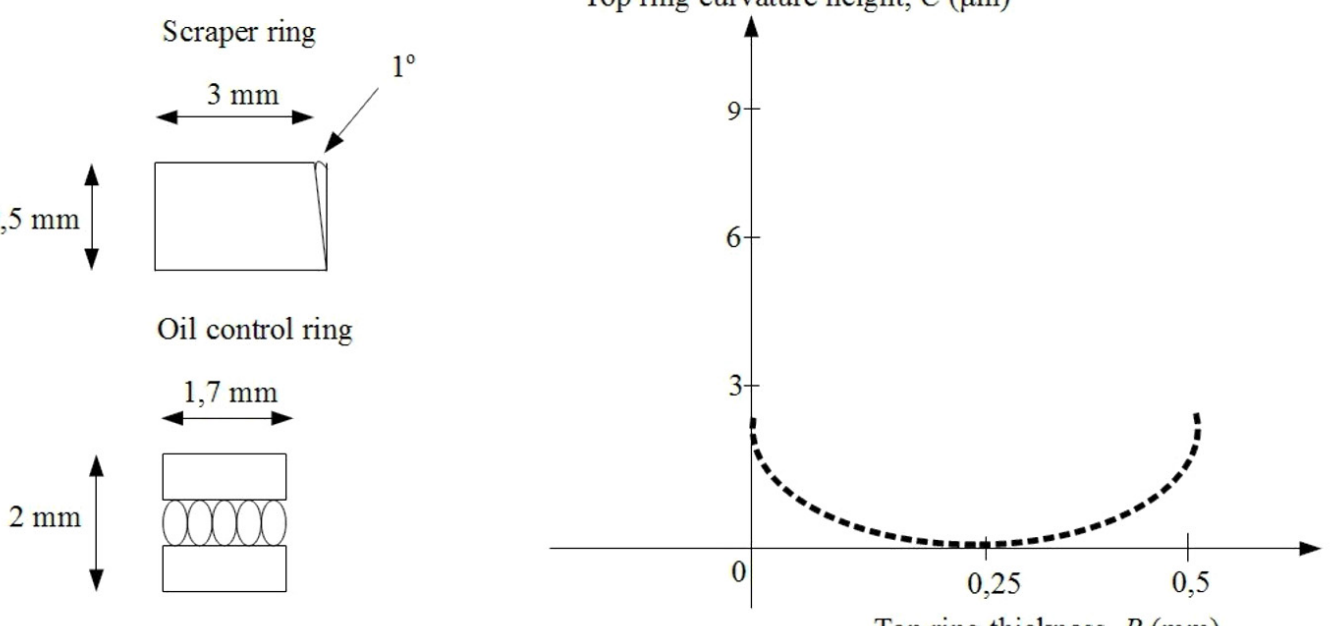

Top ring thickness, $B(\mathrm{~mm})$

Fig. 1. Piston ring pack geometry of a four stroke motorbike engine.

interactions at the dead centres were taken into account by means of the Greenwood-Tripp model. To study the lubricating ability of the compression ring close to the actual conditions, variation of the lubricant oil density and viscosity is considered in this study.

\subsection{Top compression ring-cylinder geometry}

In this paper a $2 \mathrm{D}$ axisymmetric geometry is assumed and the basic dimensions of the top compression ring and the cylinder inner liner were measured by a 3D coordinate measuring machine having an accuracy of $1 \mu \mathrm{m}$ per axis. In Figure 1, a schematic view of the piston ring pack and the top compression ring shape are illustrated. The top ring axial profile was obtained by an ideal parabola in the present analysis. However, compression rings profiles that are not symmetrical caused significant changes in the contact, hence it is necessary to analyse the real profiles for the future investigation in this study.

The first compression ring is a chromium plated steel ring characterized by radial width $W=3.35 \mathrm{~mm}$ and a thickness of $B=0.5 \mathrm{~mm}$. The top ring surface roughness is $\sigma_{\mathrm{r}}=0.25 \mu \mathrm{m}$ and the bore surface roughness is $\sigma_{\mathrm{cyl}}=$ $0.1 \mu \mathrm{m}$ as obtained from surface topography measurements. The cylinder bore is assumed to be a complete circular cylinder with nominal diameter $D_{\text {cyl }}=52 \mathrm{~mm}$ and the piston-ring end gap is taken as $d_{\text {gap }}=0.2 \mathrm{~mm}$. Complete data regarding the top compression ring-cylinder geometry, material properties and operating parameters values are presented in Table 1.

\subsection{Assumptions and lubrication theory}

The following assumptions for the top piston ringcylinder model are made: the flow is considered laminar and two dimensional; the ring twist effects are ignored; the body forces are considered and the piston-cylinder system is assumed to be concentric assembled.

In actual engines, rings twist during the course of change of direction. This phenomenon occurs more often in piston rings with a non-rectangular cross section, which change position by twisting and arching in the axial direction. In the present analysis, a non-chamfered piston ring is considered to consolidate in the top compression ring curvature effects by neglecting the twist effects. For the current analysis, the in-plane simulation has a significantly reduced computation time, due to the lower complexity than that of the out-of-plane ring dynamic motion. However, when the operating engine conditions are more severe and the oil starvation model is included, then the three-dimensional ring dynamics should be considered. This point will be investigated later on to examine the significance of the ring twist into the piston groove regarding the ring's sealing capability.

In the current work, a 2D axisymmetric FLOTRAN/CFD model is created using the finite element method. The piston ring lubrication problem is very complex, and no publication takes into account all the phenomena at once. This simulation is based on the NavierStokes equations solution. Unlike the Reynolds equation, with the Navier-Stokes approach, the pressure gradient 
Table 1. Top compression ring-cylinder conjunction characteristics and operating engine conditions.

\begin{tabular}{ccc}
\hline Parameter & Value & Unit \\
\hline Motorbike engine type & four stroke,air cooled & - \\
Motorbike volume & 107 & $\mathrm{cc}$ \\
Nominal cylinder diameter, $D_{\text {cyl }}$ & 52 & $\mathrm{~mm}$ \\
Crank-pin radius, $r$ & 25 & $\mathrm{~mm}$ \\
Rod length, $l_{\text {rod }}$ & 96 & $\mathrm{~mm}$ \\
Idle rotational speed, $\Omega_{\text {idle }}$ & 1000 & $\mathrm{rpm}$ \\
Maximum rotational speed, $\Omega_{\mathrm{max}}$ & 7500 & $\mathrm{rpm}$ \\
Compression ring thickness, $B$ & 0.5 & $\mathrm{~mm}$ \\
Compression ring width, $W$ & 3.35 & $\mathrm{~mm}$ \\
piston-ring end gap, $d_{\text {gap }}$ & 0.2 & $\mathrm{~mm}$ \\
Roughness of compression ring, $\sigma_{\mathrm{r}}$ & 0.25 & $\mu \mathrm{m}$ \\
Roughness of cylinder wall, $\sigma_{\text {cyl }}$ & 0.1 & $\mu \mathrm{m}$ \\
Average cylinder temperature, $T_{\mathrm{av}}$ & 43 & ${ }^{\circ} \mathrm{C}$ \\
Compression ring material & Chromium plated steel & - \\
Young's modulus of elasticity for ring, $E_{\mathrm{r}}$ & 279 & $\mathrm{GPa}$ \\
Compression ring Poisson's ratio, $\nu_{\mathrm{r}}$ & 0.21 & - \\
Cylinder block material & Aluminium & - \\
Young's modulus of elasticity for cylinder, $E_{\text {cyl }}$ & 70 & $\mathrm{GPa}$ \\
Cylinder Poisson's ratio, $\nu_{\mathrm{cyl}}$ & 0.33 & - \\
\hline
\end{tabular}

across the lubricant film is taken into account, which leads to more accurate evaluation of viscous friction due to Poiseuille lubricant flow [21,25]. However, in this analysis, the vapour transport model is not considered and sequentially the void volume fraction cannot be evaluated, like in Shahmohamadi et al. [22].

The research contribution by Shahmohamadi et al. [21, 22] considered the Navier-Stokes equations solution, with substantial numerical results at medium loads and higher piston speeds. In fact, CFD predictions have shown better agreement with the experimental results [11] in relation to those from the Reynolds equation solution under the full-hydrodynamic lubrication regime. Furthermore, the open cavitation exit boundary condition is assumed in their model, which is more applicable for the complicated problem of piston ring lubrication [26].

To examine the CFD analysis computed results, a comparison can be depicted with Elrod's model [21] and the basic Reynolds equation. In particular, the top compression ring of the high performance V12 four-stroke engine is simulated. Regarding the basic ring geometric dimensions, the ring axial face-width was obtained by an ideal parabola characterized by radial width $W=3.5 \mathrm{~mm}$ and a thickness of $B=1.475 \mathrm{~mm}$. The main input boundary conditions are almost the same as the work of Shahmohamadi et al. [22]. Figure 2 shows the computed pressure profile along the barrel-faced ring at a crank angle of +10 degrees when high combustion pressure acts on the top compression ring for a rotational speed of $2000 \mathrm{rpm}$ and isothermal conditions. Good conformance is observed between the current investigation and the Elrod model. On the other hand, the computed pressure profile completely described in the full lubrication regime is based on the basic Reynolds approach. Nevertheless, although this is a very fast analysis, mass conservation of the fluid in the cavitation zone is not attained. In

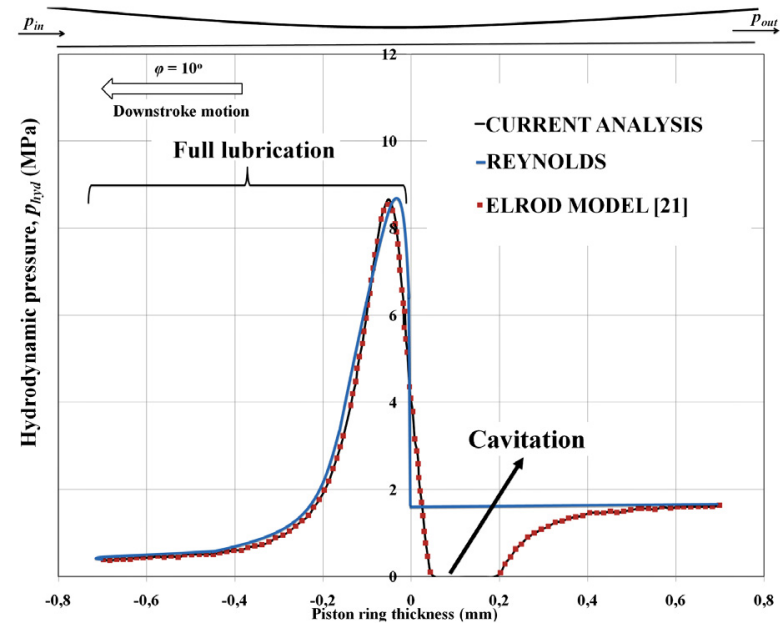

Fig. 2. Hydrodynamic pressure profile along the ring thickness at power stroke for three different algorithms.

addition, the analysis of Shahmohamadi et al. [21] showed that the pressure profiles have a good agreement between Elrod's model and the Navier-Stokes solution at low speed and high load. With regard to the high speed and medium load case, there is a marginal difference on the film rupture point between the current analysis and the Elrod model. However, this point is not the scope of the current investigation. Here, the results from an accurate simulation model are presented, obtaining data from a medium level, 107 cc motorbike engine.

\subsection{Governing equations}

The generated hydrodynamic pressures into the ringcylinder conjunction are obtained using Navier Stokes equations [28]. The momentum equation, is coupled with 
the continuity equation and solved using the finite volume method. In the present paper, the conservation equations for laminar flow (in an inertial, non-accelerating, reference frame) are presented.

\section{Mass conservation equation}

The equation for conservation of mass, or continuity equation, can be written as [28]:

$$
\frac{D \rho}{D t}+\rho \nabla \vec{V}=0
$$

Equation (1) is the general form of the mass conservation equation and is valid for incompressible as well as compressible flows.

\section{Momentum conservation equation}

Conservation of momentum is expressed by [28]:

$$
\rho \frac{D \vec{V}}{D t}+\rho \nabla \vec{V}=-\nabla p+\nabla \cdot(\bar{\tau})+\vec{F}
$$

where $\rho$ is the lubricant density, $\vec{V}$ is the fluid velocity vector, $p$ is the pressure, $\bar{\tau}$ is the viscous stress tensor and $\vec{F}$ is the external body force accordingly. In particular, the velocity vector $\vec{V}=V \hat{i}+U \hat{j}+W \hat{k}$ represents the following parameters: $V$ is the component of velocity in the radial direction (which is not accounted for a thin ring-cylinder interface), $U$ is the component of velocity in the axial direction (oil flow entertainment into the ringcylinder clearance) lubricant flow entrainment; and $W$ is the squeeze film velocity.

The stress tensor $\bar{\tau}$ is defined as:

$$
\bar{\tau}=\mu\left[\left(\nabla \vec{v}+(\nabla \vec{v})^{T}\right)-\frac{2}{3} \nabla \cdot \overrightarrow{\bar{v}}\right]
$$

where $\mu$ is the lubricant viscosity and the second term on the right hand side is the effect of volume dilation.

\section{Boundary conditions}

This model deals with the effect of the in-plane compression ring motion in quasi-static equilibrium. The algorithm was updated at any crank angle by considering the piston speed, the minimum lubricant film, the combustion pressure and the asperity load. External and internal forces acting in the radial direction, perform the tribological behaviour of the top compression ring profile.

\subsection{Compression ring motion}

In reality, the piston ring motion consists of a radial and axial movement across to cylinder wall. In this study, the top ring moved in the axial direction ( $y$-axis) according to the piston motion as mentioned by $[12,15]$. In specific, the lubricant side leakage ( $x$-axis) is ignored for thin oil films between the ring liner and cylinder wall.
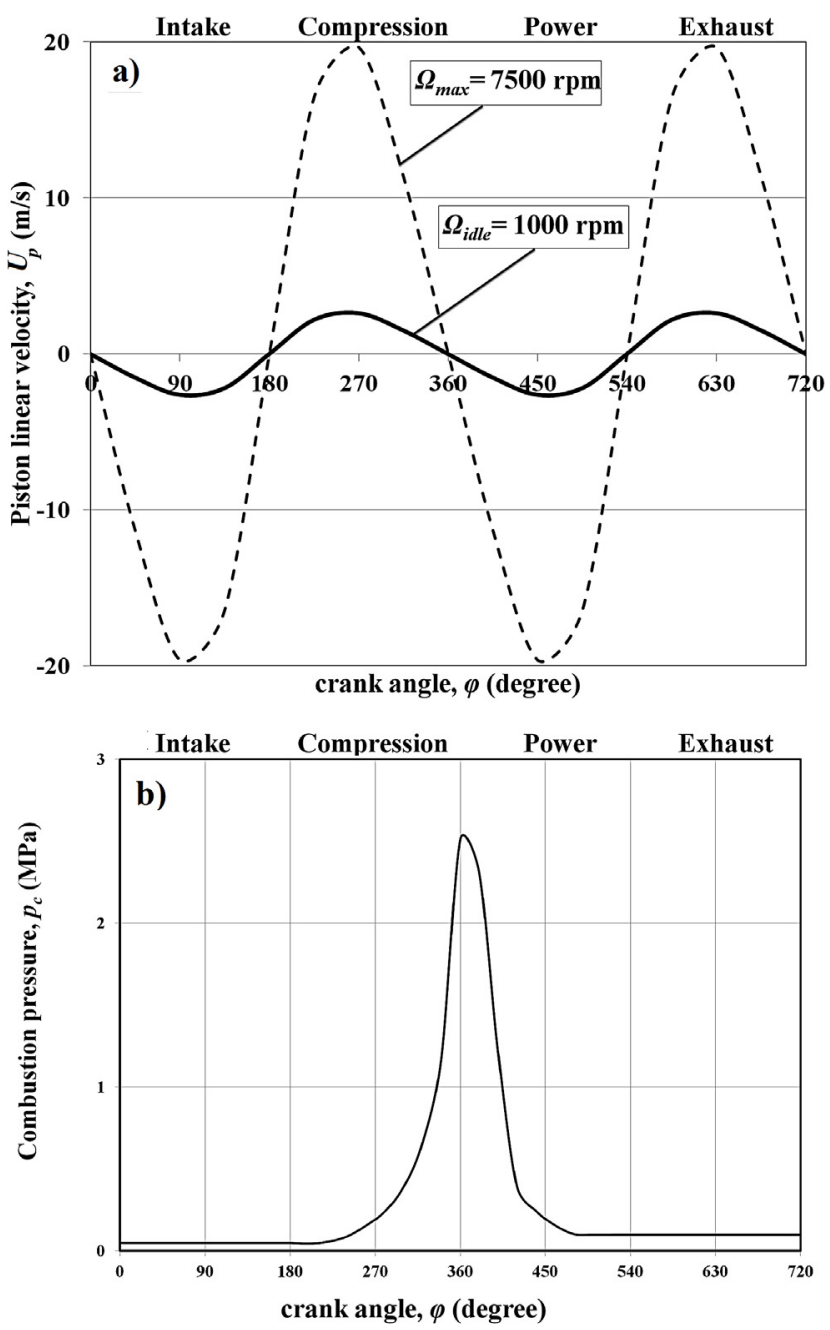

Fig. 3. (a) Piston linear velocity versus crank angle at idle and maximum rotational crankshaft speeds, (b) combustion gas pressure versus crank angle.

Therefore, in the described motorbike engine the piston starts to move upward from bottom dead centre (BDC) and for the crank angle $180^{\circ}$. In Figure 3 a the variation of the piston speed of this motorbike engine at different rotational speeds is presented and it is given by the expression:

$$
U_{\mathrm{p}}(\varphi)=r \Omega\left(\sin \varphi+\frac{\lambda_{\mathrm{CR}}}{2} \sin 2 \varphi\right)
$$

where $r$ is the crank-pin radius, $\Omega$ is the rotational crankshaft speed, $\varphi$ is the crank angle and $\lambda_{\mathrm{CR}}$ is the control ratio.

For the certain four stroke motorbike engine, the combustion pressure inside the engine is obtained by reference [27] and illustrated in Figure 3b. In particular, the in-cylinder pressure produces high radial loads on the top compression ring, causing the ring movement towards cylinder liner. Thus, the radial motion of the compression ring was represented by the lubricant film thickness. In Figure 4 a schematic view of the top compression 


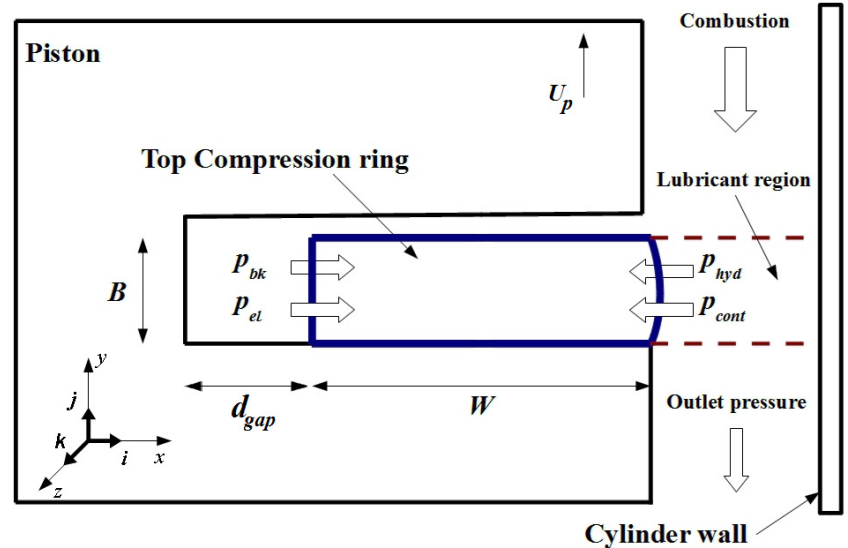

Fig. 4. Schematic view of the top compression ring-cylinder conjunction.

ring-cylinder conjunction is illustrated. The lubricant film thickness between the compression ring and the cylinder inner liner is expressed as:

$$
h(y, t)=h_{\min }(t)+\underbrace{\frac{C}{\left(\frac{B}{2}\right)^{2}} y^{2}}_{\mathrm{h}_{\mathrm{s}}(\mathrm{y})}+\delta_{\mathrm{r}}+\delta_{\mathrm{cyl}}
$$

where $h_{\min }(t)$ is the minimum oil thickness of piston ring-cylinder interface at any time, $h_{\mathrm{s}}(y)$ is the artificial parabola shape and $\delta_{\mathrm{r}}, \delta_{\text {cyl }}$ are the roughness amplitudes for the ring and the cylinder accordingly. The local contact deformation and the thermoelastic contribution are not considered in expression (5). Actually, the relevant published papers $[9,10,12]$ show that the local elastic asperity contact is insignificant. In addition, the effects of thermal distortions to ring-cylinder interface, the cylinder bore out-of-roundness and compression ring/liner conformability are not in the scope of the current analysis.

\subsection{Hydrodynamic lubrication model}

Rapidly changing running engine conditions could lead to mixed and fully flooded lubrication regime in front of the moving ring liner. The proposed model simulates the in plane compression ring motion by the load equilibrium (see Eq. (6)) in quasi-static conditions. In practical terms, the generated pressures in the ring-cylinder clearance $p_{\text {tot }}(\varphi)=p_{\text {hyd }}(\varphi)+p_{\text {cont }}(\varphi)$ are same with the ring tension of the ring and the back pressure from the combustion.

$$
\begin{aligned}
& \underbrace{p_{\text {el }} B \frac{D_{\text {cyl }}}{2}}_{\text {elastic force }}+\underbrace{\pi D_{\text {cyl }} B p_{\text {bk }}(\varphi)}_{\text {back gas force }}=\underbrace{\pi D_{\text {cyl }} \int_{-\frac{B}{2}}^{\frac{B}{2}} p_{\text {hyd }}(\varphi) \mathrm{d} x \mathrm{~d} y}_{\text {hydrodynamic generated force }} \\
&+\underbrace{W_{\text {cont }}(\varphi)}_{\text {asperities generated force }}
\end{aligned}
$$

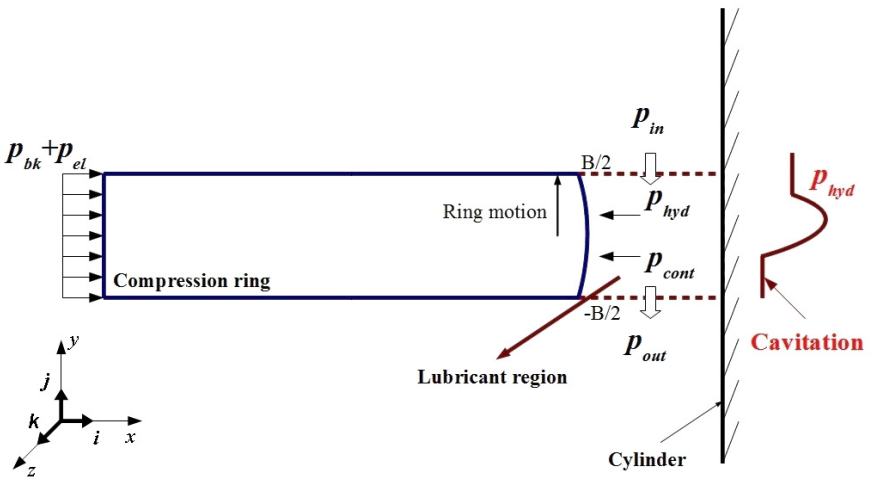

Fig. 5. Flow boundary conditions of the compression ringcylinder conjunction.

In particular, the elastic pressure is defined as $p_{\mathrm{el}}=$ $\frac{d_{\text {gap }} E_{\mathrm{r}} I_{r}}{3 \pi B\left(\frac{D_{\mathrm{cyl}}}{2}\right)^{4}}$ for the top ring cross section parameter, $I_{\mathrm{r}}=$ $\frac{B W^{3}}{12}$. With regard to the back gas pressure value, the total in-cylinder pressure is considered.

Figure 5 shows the boundary input conditions at the upper and lower edges of the top compression ring respectively. The simulation model, based on lubrication theory, considers fully flooded inlet conditions while in the convergent-divergent region the lubricant film ruptures due to the development of cavitation. In specific, the combustion and the outlet boundary pressures are defined in relation with the piston motion. The outlet pressure is assumed to be the atmospheric pressure $p_{\mathrm{a}}=0.1 \mathrm{MPa}$. In Equation (7) the variation of the boundary input pressures is represented as below:

$$
\left\{\begin{array}{l}
p\left(x, \frac{B}{2}\right)=\left\{\begin{array}{l}
p_{\text {in }}=p_{\mathrm{c}}->\text { Upstroke motion } \\
p_{\text {out }}=p_{\mathrm{c}}->\text { Downstroke motion }
\end{array}\right. \\
p\left(x,-\frac{B}{2}\right)=\left\{\begin{array}{l}
p_{\text {out }}=p_{\mathrm{a}}->\text { Upstroke motion } \\
p_{\text {in }}=p_{\mathrm{a}}->\text { Downstroke motion }
\end{array}\right. \\
p_{\mathrm{bk}}(\varphi)=p_{\mathrm{c}}(\varphi)
\end{array}\right.
$$

At any crankshaft position, the piston velocity, the elastic pressure and the contact pressure are determined separately. Therefore, in the radial direction of the compression ring contact the load balance criterion is attained as follows:

$$
X=\left|\frac{\left[p_{\text {cont }}(\varphi)+p_{\text {hyd }}(\varphi)\right]-\left[p_{\text {el }}+p_{\text {bk }}(\varphi)\right]}{\left[p_{\text {el }}+p_{\text {bk }}(\varphi)\right]}\right| \leqslant 0.1 \%
$$

If the balance criterion is not achieved, then the minimum oil thickness $h_{\min }(t)$ is re-calculated through minimum lubricant film iterative loop (9). In this analysis the value of the parameter $\varepsilon$ is taken as: $\varepsilon=0.03$. Using this value the typical solution time varied between 10 and 20 min as well as the simulations were performed on the computer 
with 8 processors Intel core i7-3770 CPU @ $3.40 \mathrm{GHz}$.

$$
\begin{aligned}
& \frac{h_{\mathrm{min}}^{N+1}-h_{\mathrm{min}}^{N}}{h_{\mathrm{min}}^{N}} \\
= & \varepsilon \frac{\left[p_{\mathrm{cont}}(\varphi)+p_{\mathrm{hyd}}(\varphi)\right]-\left[p_{\mathrm{el}}+p_{\mathrm{bk}}(\varphi)\right]}{\max \left[p_{\mathrm{cont}}(\varphi)+p_{\mathrm{hyd}}(\varphi), p_{\mathrm{el}}+p_{\mathrm{bk}}(\varphi)\right]}, \text { for } N \geqslant 1
\end{aligned}
$$

\subsection{Boundary/Mixed lubrication model}

Thin oil film at the ends of the piston stoke increased the direct interaction of the asperities on the sliding surfaces. Therefore, a part of the top ring surface suffers by the asperities contact. In the current study, the Greenwood-Tripp model [17] was studied between two rough surfaces like as ring-cylinder tribo pair. The asperity height distribution is Gaussian, thus the generated contact pressure, $p_{\text {cont }}=\frac{W_{\text {cont }}}{A_{\text {cont }}}$, by normally distributed asperity heights can be defined by the following expressions:

$$
\left\{\begin{array}{l}
W_{\mathrm{cont}}=\frac{8 \sqrt{2}}{15} \pi\left(\zeta \kappa \sigma_{\mathrm{rms}}\right)^{2} \sqrt{\frac{\sigma_{\mathrm{rms}}}{\kappa}} E^{\prime} A F_{5 / 2}(\lambda) \\
A_{\mathrm{cont}}=\pi^{2}\left(\zeta \kappa \sigma_{\mathrm{rms}}\right)^{2} A F_{2}(\lambda) \\
\frac{1}{E^{\prime}}=\frac{1}{2}\left(\frac{1-\nu_{\mathrm{r}}^{2}}{E_{\mathrm{r}}}+\frac{1-\nu_{\mathrm{cyl}}^{2}}{E_{\mathrm{cyl}}}\right)
\end{array}\right.
$$

In Equation (10), the terms $\zeta \kappa \sigma_{\mathrm{rms}}=0.040$ and $\frac{\sigma_{\mathrm{rms}}}{\kappa}=$ 0.0015 are the roughness parameter and the asperity slope respectively and $\sigma_{\mathrm{rms}}=\sqrt{\sigma_{\mathrm{r}}^{2}+\sigma_{\text {cyl }}^{2}}=0.27 \mu \mathrm{m}$ considers the root mean square surface finish of contact surfaces. $E^{\prime}$ is the effective elastic modulus of the examined tribo pair and $A=\pi D_{\text {cyl }} B$ is the apparent smooth contact area. In addition, the statistical functions $F_{5 / 2}(\lambda), F_{2}(\lambda)$ are obtained as a relation of the Stribeck oil film parameter $\lambda=h / \sigma_{\mathrm{rms}}$. As follows, these functions are of the form:

$$
F_{\mathrm{j}}(\lambda)=\frac{1}{2 \pi} \int_{\lambda}^{\infty}(s-\lambda)^{j} \exp \left(-\frac{s^{2}}{2}\right) \mathrm{d} s
$$

To this point, the probability distribution of asperity heights $F_{5 / 2}(\lambda), F_{2}(\lambda)$ are defined by a fifth-order polynomial curve as given by references $[15,21]$.

$$
\begin{array}{r}
F_{5 / 2}(\lambda)=-0.0046 \lambda^{5}+0.0574 \lambda^{4}-0.2958 \lambda^{3} \\
+0.7844 \lambda^{2}-1.077 \lambda+0.6167 \\
F_{2}(\lambda)=-0.0018 \lambda^{5}+0.0281 \lambda^{4}-0.1728 \lambda^{3} \\
+0.5258 \lambda^{2}-0.8043 \lambda+0.5003
\end{array}
$$

Statistical contact models are a practical method of determining the asperity contact pressure between the ring and liner for a given mean separation of the contact surfaces and are presently the most common method of modelling mixed and boundary lubrication regimes. Greenwood and Tripp's asperity contact model [17] for two nominally flat, rough surfaces is a common model used by researchers to account for asperity contact in modelling the piston ring pack. The development of flow factors by Patir and Cheng [14] enabled the effect of surface roughness on lubricant flow behaviour, which is important in understanding oil consumption, to be included in ring-pack modelling. Flow factors adjust the solution of the Reynolds equation for the effects of surface roughness. However, both asperity contact and flow resistance models are typically applied assuming Gaussian surface roughness.

The piston ring-cylinder tribological pair is in surface contact during engine operation. Topographical changes during running-in can affect the performance and efficiency of a piston tribo system. Many studies have attempted to investigate the changes of surface topography during running-in of the engine by ignoring the plastic deformation. Most of those studies are limited to Gaussian surfaces under simple abrasive wear conditions. However, there are several applications whose surfaces are non-Gaussian. In addition, running-in wear is not limited to simple abrasive type. Therefore, a more comprehensive wear model that can analyse the wear problem for both Gaussian and non-Gaussian surfaces is needed.

\subsection{Temperature and viscosity properties}

The simulation is conducted close to the actual conditions of the aforementioned motorbike engine speeds. This four-stroke motorbike engine operated at idle $\mathrm{rpm} \Omega_{\text {idle }}=$ $1000 \mathrm{rpm}$ and at maximum speed $\Omega_{\max }=7500 \mathrm{rpm}$, corresponding to the engine performance. In particular, the variation of the cylinder block temperature is presented using data from a high-performance thermo camera type: FLIR SC660 with $640 \times 480$ resolution and $\pm 1 \%$ accuracy. For such measurements, a thermocouple circuit could also be used. The temperature displayed by a thermocouple is the temperature of the thermocouple. One of the most difficult items to realize is the bonding or adhering of the thermocouple to the part whose temperature is desired. Improper bonding will cause a lower temperature of the component that you are attempting to measure to be displayed. An infrared camera is a non-contact measurement instrument where this problem does not exist. The above reason and some other drawbacks of thermocouples, such as the alternation of the electrical characteristics of the circuit, the open thermocouple junction, and their decalibration, can result in an error in measurement, so the authors used a thermal camera instead of thermocouples. Figure 6 shows a picture of the cylinder's block temperature distribution under warm idle rotational conditions. As Morris et al. [13] have noted, the increment of the oil temperature through shear is marginally higher than the cylinder liner temperature; thus, the lubricant temperature is equal to the cylinder's liner temperature at each position. Therefore, the oil temperature can be estimated using the average cylinder's liner temperature 


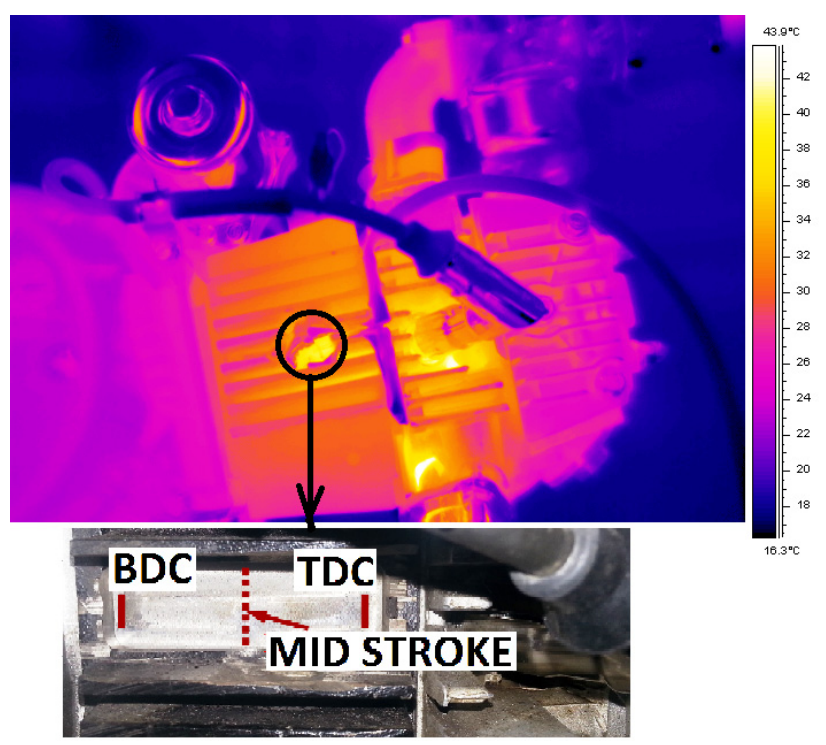

Fig. 6. Cylinder block temperature distribution under warm idle running engine conditions.

for warm idle conditions because the energy equation is not accounted for. Additionally, for simplicity, the current analysis also estimates that the cylinder temperature remains constant throughout the piston speed increment.

Therefore, the lubricant density and dynamic viscosity can be described as a function of generated pressure and temperature as given by references [29-31]:

$$
\begin{aligned}
& \rho=\rho_{0}\left(1+\frac{6 \times 10^{-10}\left(p_{\text {hyd }}-p_{\text {atm }}\right)}{1+1.7 \times 10^{-9}\left(p_{\text {hyd }}-p_{\text {atm }}\right)}\right) \\
& \times\left[1-0.65 \times 10^{-3}\left(T_{\mathrm{av}}-T_{0}\right)\right] \\
& \mu=\mu_{0} \exp \left\{( \operatorname { l n } \mu _ { 0 } + 9 . 6 7 ) \left[\left(\frac{T_{\mathrm{av}}-138}{T_{0}-138}\right)^{-S_{0}}\right.\right. \\
& \left.\left.\times\left(1+\frac{p_{\text {hyd }}-p_{\text {atm }}}{1.98 \times 10^{8}}\right)^{Z_{0}}-1\right]\right\}
\end{aligned}
$$

where the parameters $S_{0}$ and $Z_{0}$ are defined as:

$$
\begin{aligned}
Z_{0} & =\frac{a_{0}}{5.1 \times 10^{-9}\left(\ln \mu_{0}+9.67\right)} \\
S_{0} & =\frac{\beta_{0}\left(T_{0}-138\right)}{\ln \mu_{0}+9.67}
\end{aligned}
$$

For this motorbike engine investigation, the fresh monograde mineral oil type MOTOR HD SAE 30 is used. In Table 2 , the main lubricant properties are presented which they are coming from the relevant oil standards.

\subsection{Total friction and power losses}

The total friction force along the top compression ring significantly contributes to the frictional losses of
Table 2. Lubricant MOTOR HD SAE 30 specifications at atmospheric pressure and ambient temperature $40{ }^{\circ} \mathrm{C}$.

\begin{tabular}{ccc}
\hline Parameter & Value & Unit \\
\hline lubricant density, $\rho_{0}$ & $858 @ 40{ }^{\circ} \mathrm{C}$ & $\mathrm{kg} \cdot \mathrm{m}^{-3}$ \\
lubricant visocsity, $\mu_{0}$ & $0.075 @ 40{ }^{\circ} \mathrm{C}$ & $\mathrm{Pa} . \mathrm{s}$ \\
specific heat, $c_{\mathrm{p}}$ & 1985 & $\mathrm{~J} . \mathrm{kg}^{-1} \cdot \mathrm{K}^{-1}$ \\
thermal conductivity, $k$ & 0.143 & $\mathrm{~W} \cdot \mathrm{m}^{-1} \cdot \mathrm{K}^{-1}$ \\
$a_{0}$ & $1 \times 10^{-8}$ & $\mathrm{~m}^{2} \cdot \mathrm{N}^{-1}$ \\
$\beta_{0}$ & $4 \times 10^{-2}$ & - \\
\hline
\end{tabular}

the engine. In practice, the mechanism of the compression ring-cylinder has led to a substantial friction increment $13-40 \%$ depending on the running engine conditions [1]. Thus, a great attention should be focused on improving the losses in order to reduce the fuel consumption. The motorbike engine total friction obtained actually comprises two sub-models (boundary/mixed and hydrodynamic conditions). The hydrodynamic friction due to viscous shear stress of the oil film behaviour and the boundary/mixed friction due to asperity contact load is calculated and summarized by Equation (18) for this simulation approach.

$$
\begin{aligned}
F_{\text {total }}=\underbrace{\left| \pm \frac{h}{2} \nabla p-\Delta \vec{V} \frac{\mu}{h}\right|\left(A-A_{\text {cont }}\right)}_{\text {viscous friction }} \\
+\underbrace{\tau_{0} A_{\text {cont }}+\mu_{\text {asp }} W_{\text {cont }}}_{\text {boundary } / \text { mixed friction }}
\end{aligned}
$$

It should be noted that the shear stress through lubricant film at hydrodynamic conditions is defined as $\tau=\left| \pm \frac{h}{2} \nabla p-\Delta \vec{V} \frac{\mu}{h}\right|$. In parallel with the boundary lubrication of the compression ring, the non-Newtonian Eyring shear stress and the boundary shear strength of the sliding surfaces are considered $\tau_{0}=2 \times 10^{6} \mathrm{~Pa}$ and $\mu_{\text {asp }}=0.17$, as noted to reference [13]. Finally, taking into account the total compression ring friction force the frictional power losses are calculated as follows:

$$
P_{\text {tot }}=F_{\text {total }}\left|U_{\mathrm{p}}(\varphi)\right|
$$

where the piston speed $U_{\mathrm{p}}(\varphi)$ is expressed by Equation (4).

\section{Fluid simulation solution}

A 2D axisymmetric model is developed using the Computational Fluid Dynamic (CFD) method. For the CFD/FLOTRAN elements, the velocities are obtained from the conservation of momentum principle, and the pressure is evaluated from the conservation of mass. A segregated sequential solver algorithm is used; that is, the matrix system derived from the finite element discretization of the governing equation for each degree of freedom which is solved separately. In the segregated algorithm the governing equations are solved sequentially, segregated 


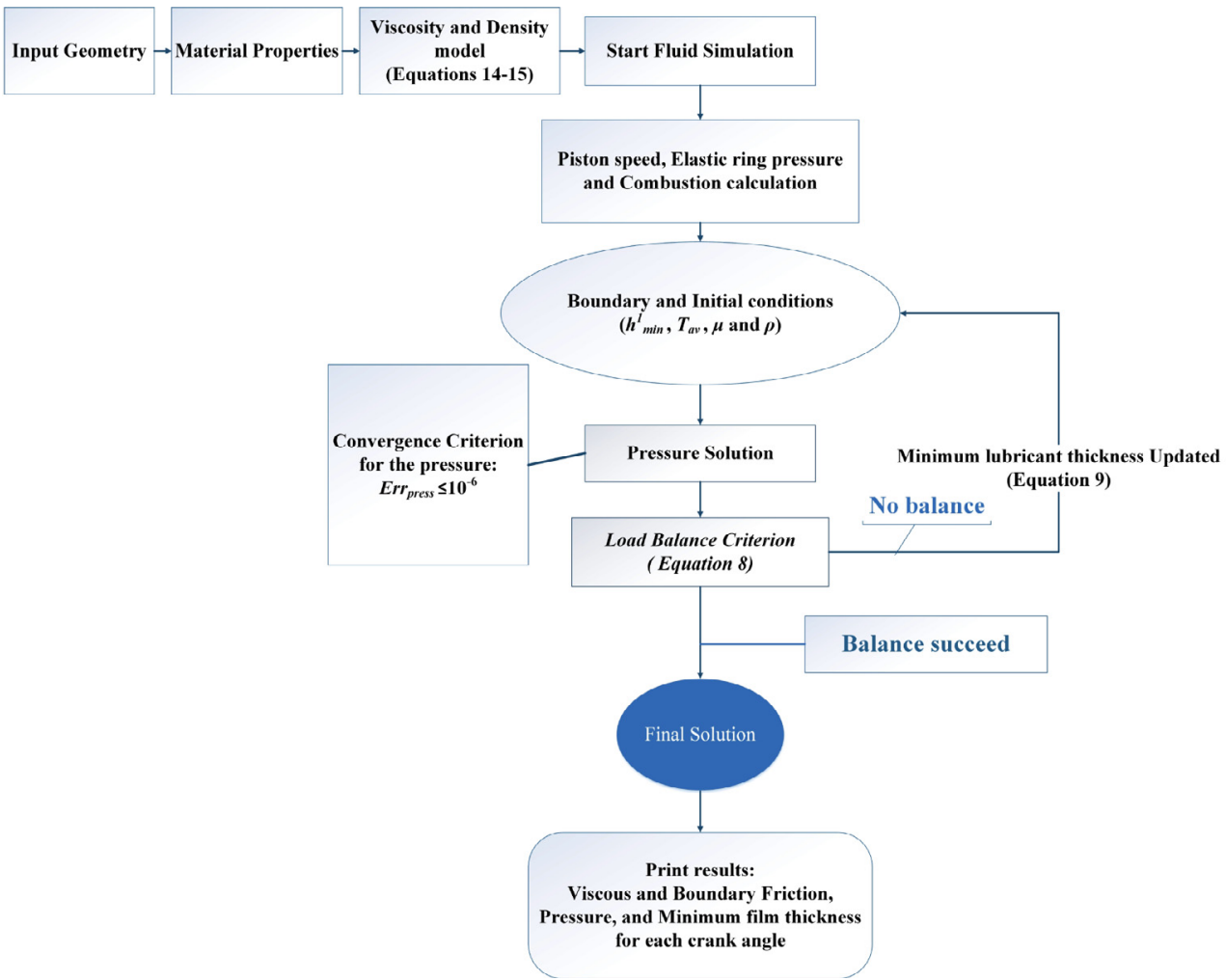

Fig. 7. Flowchart of the fluid simulation model solution.

from one another, while in the coupled algorithm the momentum equations and the pressure-based continuity equation are solved in a coupled manner. In general, the coupled algorithm significantly improves the convergence speed over the segregated algorithm, however, the memory requirement for the coupled algorithm is more than the segregated algorithm. The flow problem is nonlinear and the governing equations are coupled together. This nonlinear solution procedure used in FLOTRAN belongs to a general class of Semi-Implicit Method for Pressure Linked Equations (SIMPLE). In this approach, the SIMPLE algorithm reduce the discretisation-induced errors in the calculations. The sequential solution of all the governing equations, combined with the update of any pressuredependent properties, constitutes a global iteration.

Figure 7 illustrates the steps of the fluid structure algorithm. Firstly, the piston linear velocity, the combustion and the ring tension are computed separately and they are given as inputs in the simulation model. Next, initial and boundary conditions about the minimum film thickness, the lubricant rheology properties and the gas pressures are obtained, thus the hydrodynamic pressure and contact pressure along the ring axial width are computed. During the simulation implementation, regarding the initial computed pressures into the ring-liner clearance the lubricant viscosity and density are adjusted as the solution occurs, therefore the generated pressures are re-calculated. If the load balance is not met, the minimum lubricant film is updated and the procedure is repeated until the equilibrium position is achieved through expression (8). Once the compression ring is in instantaneous plane-equilibrium, then the solution is stored. Convergence in final solution for the mixed hydrodynamic lubrication problem is obtained when both pressure and load balance criteria are attained simultaneously, after 4000 iterations, and then the simulation moves to the new crank angle. Consequently for greater accuracy, the convergence tolerance is assumed to be equal $10^{-6}$ for all residual terms. Regarding the solution time, the analysis is deemed after $20 \mathrm{~min}$, and for the convergence criterion of the pressure solution the following expression used as follows:

$$
E r r_{\text {press }}=\frac{\sum_{i=1}^{i=N_{n}^{C F D}}\left|p_{i}^{k}-p_{i}^{k-1}\right|}{\sum_{i=1}^{i=N_{n}^{C F D}}\left|p_{i}^{k}\right|} \leqslant 1 \times 10^{-6}
$$

\subsection{Fluid meshing discretization}

In practice, it may be useful to discuss the choice of mesh solving CFD problems for steady-state analysis. Regarding the fluid solution, tetrahedral elements are used in this simulation, which was chosen based on the convergence considerations, the mesh quality and the local mesh refinement ability. However, simple hexahedral elements could also be used for the solution. Of course, the necessary convergence and the mesh quality have to be extensively examined. In particular, the compression 


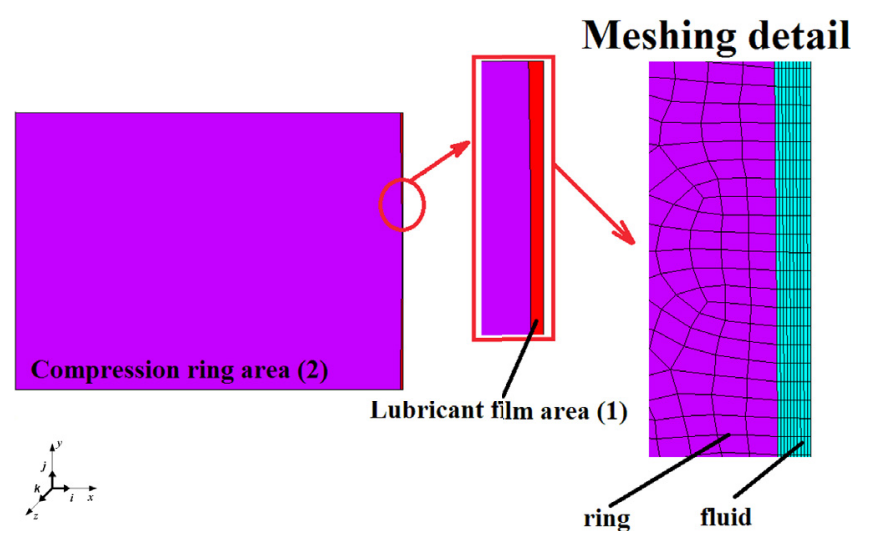

Fig. 8. Corresponding geometry and discretization details of the fluid region.

ring-cylinder conjunction geometry was designed with two areas as it is illustrated in Figure 8. The area colored red (1) simulates the lubricant film by considering a grid of $10 \mathrm{X} 500$ elements to the $x, y$ directions and the piston ring colored dark blue area (2) has a grid of $100 \times 500$ elements. Every area was meshed separately with its own grid. After extensively grid sensitivity tests, ten divisions were used in the radial direction and 500 divisions were used in the axial direction. Using lower number of divisions in the radial direction, the model gave an error between $20-25 \%$. After that, using maximum of 10 divisions, this error is minimized near to $1-2 \%$. At the same time, increasing the number of the divisions in the axial direction, from 500 to 600 , the error of numerical prediction was smaller than $0.5 \%$. It is necessary to refer that this configuration of fluid meshing is in a very good conformance with the published computed results of Shahmohamadi et al. $[21,22]$.

\section{Fluid modelling validation}

Some computational results concerning the piston ring friction force are presented by Zavos and Nikolakopoulos [23-25]. In particular, these results are compared with the numerical investigations of Sonthalia et al. [18] and Hamatake et al. [20]. Considering the strain gauge method [24], the experimental friction results of a four-stroke motor engine are compared with the computed results for fully hydrodynamic conditions.

In this simulation, the computed results were obtained from an improved model that simulates the in-plane compression ring motion by considering boundary/mixed lubrication. The results are validated against the results of a parabola-faced compression ring proposed by authors Shahmohamadi et al. [21,22] under thermo-mixed lubrication taking into account the Navier-Stokes equations solution. In practical terms, the top compression ring of a high-performance V12 four-stroke engine is modelled. Regarding the basic ring geometric dimensions, the ring axial face-width was obtained by an ideal parabola characterized by radial width $W=3.5 \mathrm{~mm}$ and a thickness
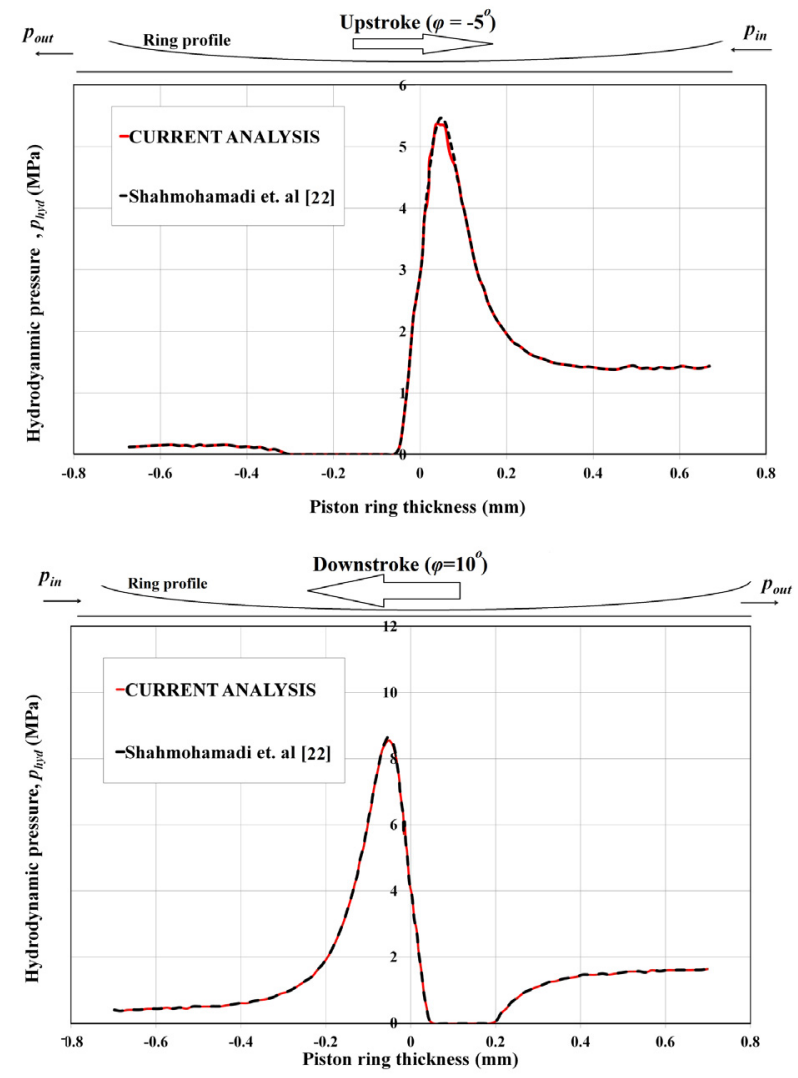

Fig. 9. Validation results. Computed values of hydrodynamic pressure at $2000 \mathrm{rpm}$, for the current and previous analysis.

of $B=1.475 \mathrm{~mm}$. Additionally, the relevant in-cylinder pressure, the piston speed and the lubricant specifications were given as inputs in the simulation. Figure 9 shows the hydrodynamic pressure distribution along the ring thickness near the top dead centre region (TDC) for a rotational engine speed $\Omega=2000 \mathrm{rpm}$. Good agreement between the computed pressure values by the current analysis and the respective published values [22] was achieved.

Additionally, it is important to verify the simulation procedure related to the experimental measurements from the literature. Furuhama et al. [11] measured the total friction force under motored engine conditions for a rotational speed of $1200 \mathrm{rpm}$. Figure 10 shows the variation of the total friction force prediction and the experimental results as presented in [11]. As expected, the line of friction follows the analysis by reference [21], whereas deviation from the experimental values is obvious. At high loads and low speeds, the Poiseuille flow around the dead centres is defined with a higher accuracy due to the first term of the shear stress equation, as follows, $\tau \sim\left( \pm \frac{h}{2} \nabla p\right)$. In the transition from the compression to power stroke through the TDC (crank angles between $340^{\circ}$ and $380^{\circ}$ ), the deviations of the predicted and measured friction force vary by $3-10 \%$. At the same time, the computed results near the mid points (Couette viscous friction) have a substantial difference of $29-35 \%$ between the experimental predictions. This difference means that the contribution of 


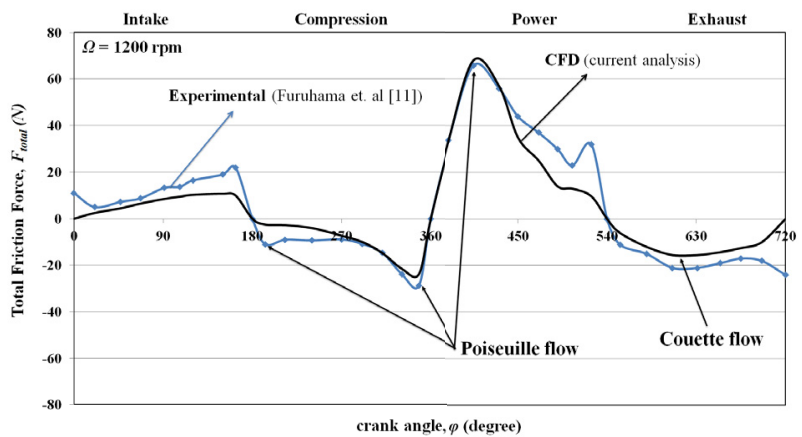

Fig. 10. Validation results. Comparison between experimental friction from Furuhama et al. [11] and computed friction from current analysis.

Table 3. Comparison between experimental and numerical minimum film thickness for a worn compression ring $(120 \mathrm{~h})$ presented in Priest et al. [3].

\begin{tabular}{ccc}
\hline $\begin{array}{c}\text { Stroke } \\
\left(\varphi=103^{\circ}\right)\end{array}$ & $\begin{array}{c}h_{\min }(\mu \mathrm{m}) \\
(\text { experimental }[3])\end{array}$ & $\begin{array}{c}h_{\min }(\mu \mathrm{m}) \\
(\text { present analysis })\end{array}$ \\
\hline Power & 0.55 & 0.9 \\
Intake & 1.2 & 1.15 \\
\hline
\end{tabular}

asperities between the ring and cylinder is essential in the experimental predictions. In particular, the non-ideal ring and cylinder profiles play an important role in the numerical prediction of the total friction due to reduced clearance. These data are not taken into account in the present investigation.

In the paper of Priest et al. [3], several worn profiles of the compression ring were measured, and the values of the minimum film thickness were compared using numerical prediction and experimental values from laser-induced fluorescence (LIF). They also provided complete data for their diesel engine, which enables the simulation. The cylinder block temperature for the top compression ring was measured at top dead centre for a constant speed and load. Hence, these data are given as inputs in our simulation model. Table 3 shows a comparison between the film thickness measurements presented by Priest et al. [3] and the computed predictions of the same conditions for the case of a worn compression ring after $120 \mathrm{~h}$ near top dead centre. The minimum lubricant thickness at each crank angle is calculated through an iterative process based on the quasi-static equilibrium ring position. The minimum lubricant thickness evaluation is improved through the intake stroke when full-hydrodynamic lubrication occurs. The roundness effects on the cylinder and the ring twist are ignored in the simulation, and the back gas pressure is assumed equal with the in-cylinder pressure. Additionally, the proposed procedure does not include any gas flow prediction through the piston ring pack, which would change the ring movement to the cylinder inner liner in the case of ring dynamics.

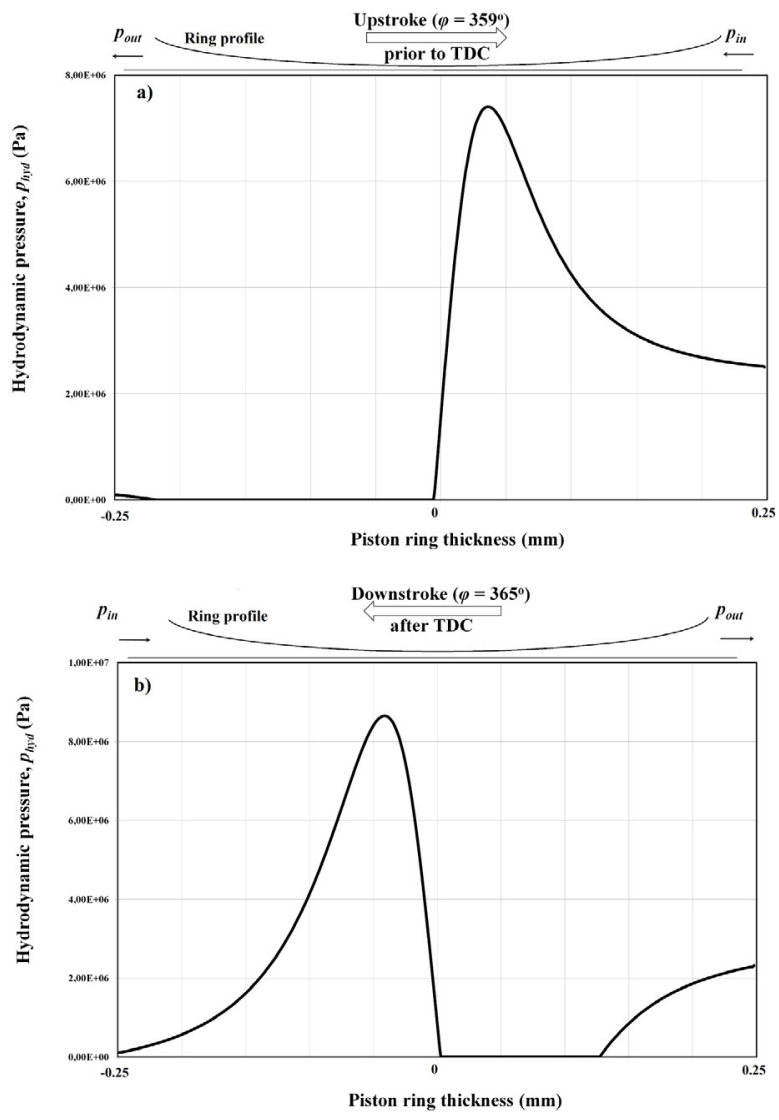

Fig. 11. Pressure profiles at idle rotational speed $1000 \mathrm{rpm}$ (a) Computed values for $\varphi=359^{\circ}$ (prior to TDC at compression stage) and (b) for $\varphi=365^{\circ}$ (after TDC at power stage).

\section{Results and discussion}

The results for the barrel-faced top compression ring of a real motorbike engine represent the tribological behaviour in boundary/mixed lubrication. The effects of the engine speed and the curvature shape were addressed under realistic engine parameters. In particular, the total friction, including power losses, the hydrodynamic pressure and the minimum film thickness, have been evaluated to optimize the compression ring curvature profile under lubrication conditions.

\subsection{Pressure, lubricant film and total friction}

Figures 11 and 12 show the pressure distribution along the compression ring thickness at idle rotational speed $\Omega_{\text {idle }}=1000 \mathrm{rpm}$ as the compression ring passes through compression to exhaust strokes. Mixed/boundary lubrication conditions were assumed at the ends of the stroke, showing the pressure gradient due to compression ring in-plane equilibrium.

In this engine, top dead centre (TDC) was defined at a crank angle of $360^{\circ}$, and the maximum combustion pressure value was considered at the crank angle $\varphi=361^{\circ}$ 


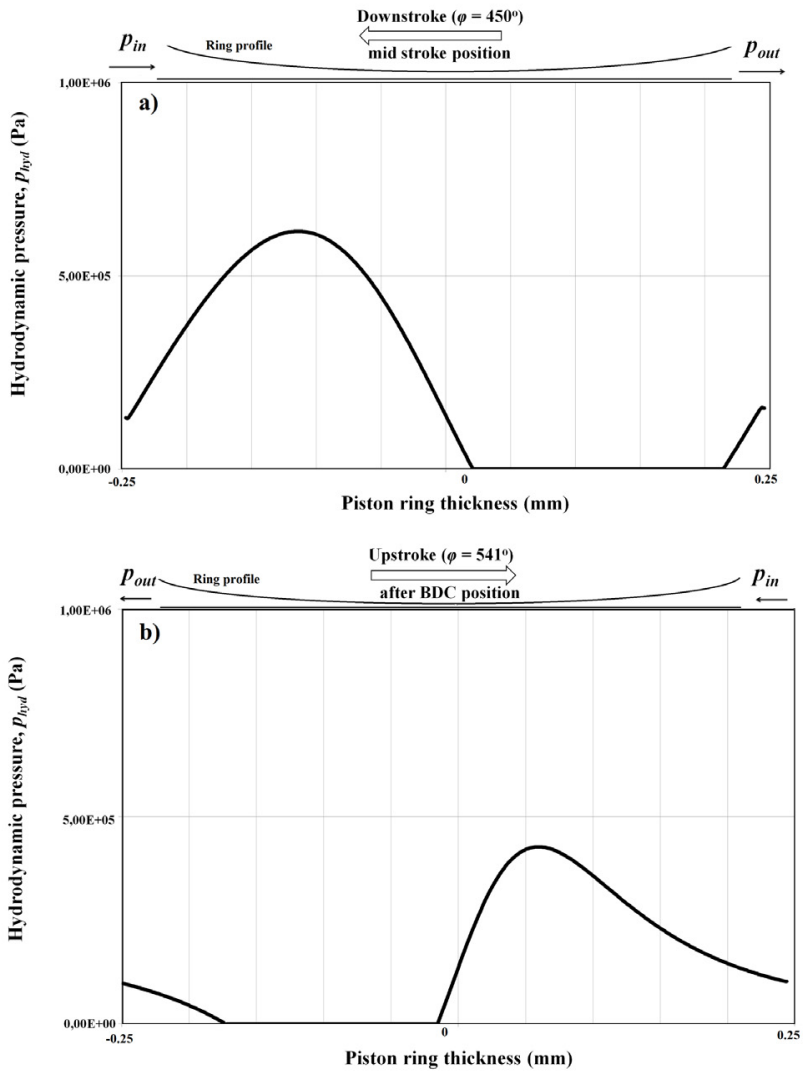

Fig. 12. Pressure profiles at idle rotational speed $1000 \mathrm{rpm}$ (a) Computed values for $\varphi=450^{\circ}$ (mid-stroke position at power stage) and (b) for $\varphi=541^{\circ}$ (after BDC at exhaust stage).

after the TDC position, as demonstrated in reference [27]. The chosen lubricant oil is a fresh Newtonian oil SAE 30 type of MOTOR HD, and the average temperature of the lubricant is assumed to be equal to the cylinder block temperature. As observed, the generated hydrodynamic pressure along the ring axial width increases around the TDC region (see Figs. 11a and 11b), and the ring reciprocates between the compression and power strokes. This response is expected because the compression ring is exposed to high contact loads (i.e., high combustion pressures) and low speeds at TDC reversal. From the previous computed pressure results, the inlet and outlet gas pressures are obtained for the barrel-faced compression ring-cylinder conjunction in relation with the piston motion. For example, in the compression stage at crank angle $359^{\circ}$, the inlet boundary pressure is $2.51 \mathrm{MPa}$ (as illustrated in Fig. 3b) and the outlet is at atmospheric pressure. These relevant boundary features are imposed at the upper and lower region of the top compression. The pressure profiles in Figures 11a and 11b have directly opposing behaviour due to the transition of piston motion at TDC reversal. Therefore, to predict the total friction forces, the viscous shear stress of the lubricant film because of the sliding motion of contiguous surfaces combined with the contact pressure through the asperity interactions is computed and summarized at each crankshaft position.

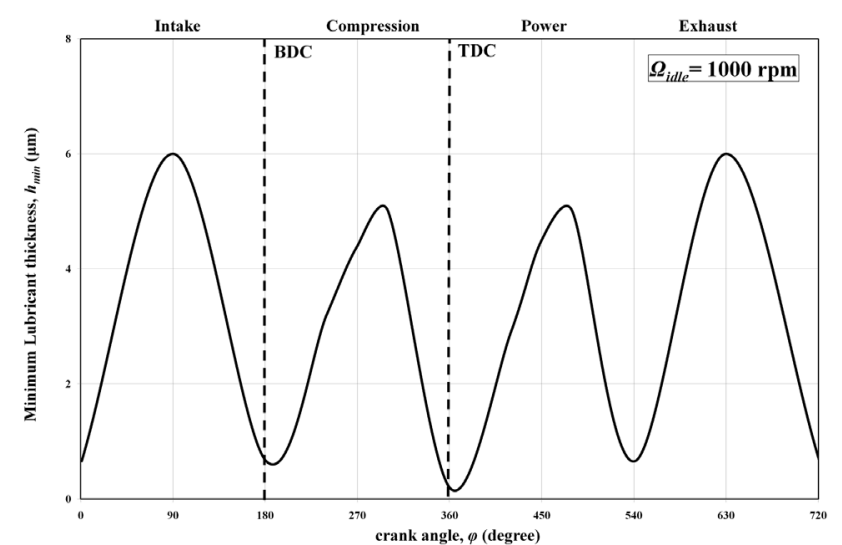

Fig. 13. Minimum lubricant thickness versus crank angle at idle rotational crankshaft speed.

At the middle of the stroke, the hydrodynamic computed pressure values are smaller than the profiles of pressure at the reversal positions. In practice, the lower gas pressures and the higher piston velocity promote the fully flooded conditions by considering thicker lubricant film to the ring-cylinder contact (see Fig. 12a). As follows from Figure 13, the variation of the minimum lubricant thickness of the parts of the engine cycle is presented. A thin lubricant film is predicted at reversal positions, and an increase of the lubricant film thickness is predicted at the mid-stroke position because the piston linear velocity is higher. For this engine investigation, the boundary and mixed regime of lubrication occurs near the TDC region, and the least amount of lubricant film varies between $0.28 \mu \mathrm{m}$ and $0.405 \mu \mathrm{m}$ at idle rotational speed. The minimum oil film value at the TDC position is approximately $0.27 \mu \mathrm{m}$, where boundary lubrication occurs $\left(\lambda=\frac{h}{\sigma_{\mathrm{rms}}}<1\right)$. In this analysis, the mixed lubrication of compression-ring contact is attained when the Stribeck oil film ratio is $\lambda=\frac{h}{\sigma_{\mathrm{rms}}}<3$. Regarding the hydrodynamic lubrication, the thicker lubricant film varies between $5 \mu \mathrm{m}$ and $6 \mu \mathrm{m}$ depending on the part of the engine stroke.

Figure 14 shows the variation of the total friction force versus the crank angle for a barrel-faced ring with curvature height $3 \mu \mathrm{m}$ to an oval bore conjunction. The boundary friction promotes the total friction at the vicinity of TDC during the power stroke. The corresponding lubricant film is quite thin in Figure 13. Therefore, the prevalent regime of lubrication is mixed with thin film asperity interactions. As the piston velocity increases, the Couette flow undergoes ring-liner clearance, forming a thicker film at the mid positions of the stroke. In practice, these computed results are for low rotational speed and realistic running motor engine conditions.

\subsection{Variation of engine speed}

It is interesting to compare the minimum film thickness and total friction for a higher rotational speed $\Omega_{\max }=7500 \mathrm{rpm}$. Figure 15 shows the trend in the 


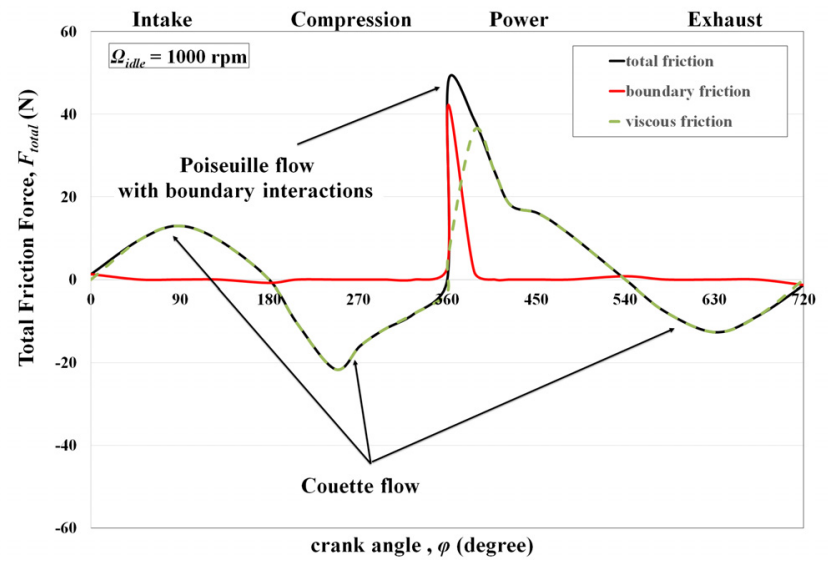

Fig. 14. Computed total friction force versus crank angle at idle rotational crankshaft speed.

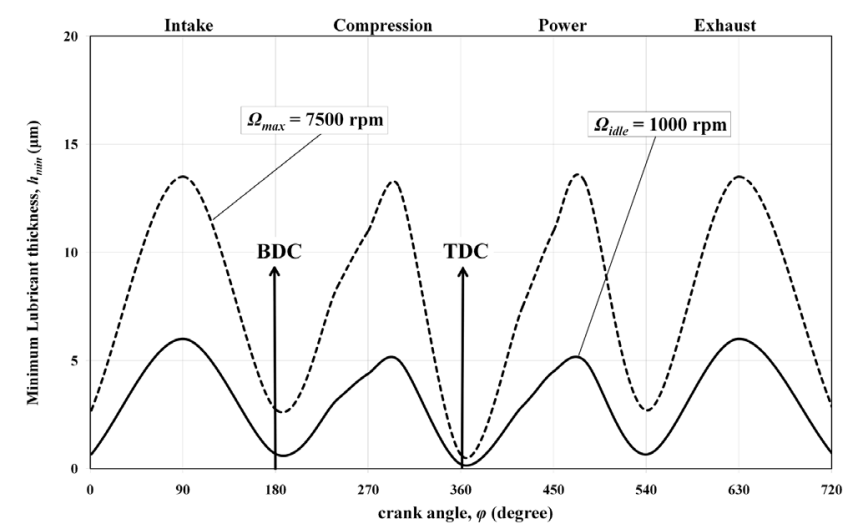

Fig. 15. Computed minimum lubricant thickness versus crank angle at idle and maximum rotational crankshaft speeds.

minimum film thickness for the cases of idle and maximum rotational speeds, corresponding to a lubricant temperature of $43{ }^{\circ} \mathrm{C}$. For simplicity, the lubricant temperature remains constant, such as the idle rotational speed, assuming that the increment of piston speed has a short duration. The least amount lubricant film is greater than $2.7 \mu \mathrm{m}$ at the TDC when the slide speed is higher; hence, the full-hydrodynamic lubrication condition of the compression ring-cylinder interface is developed. As shown in Figure 15, the minimum lubricant film becomes thicker during the middle of each stroke than in the idle speed case. The minimum lubricant film thickness varies between $7.5 \mu \mathrm{m}$ and $13.5 \mu \mathrm{m}$ at the maximum piston speeds. The computed results of these cases are compared under the fully flooded inlet lubrication regime.

Figures 16 and 17 show the total friction force and the power loss variations computed for two rotational engine speeds. The higher piston velocity ensures a marginal asperity friction, particularly at the TDC and in the power stroke. The inset to Figure 16 shows the variation of the boundary friction in the aforementioned region for maximum rotational speed. When the piston speed is increased, the viscous friction in the mid-points may be much higher than that under idle rotational speed,

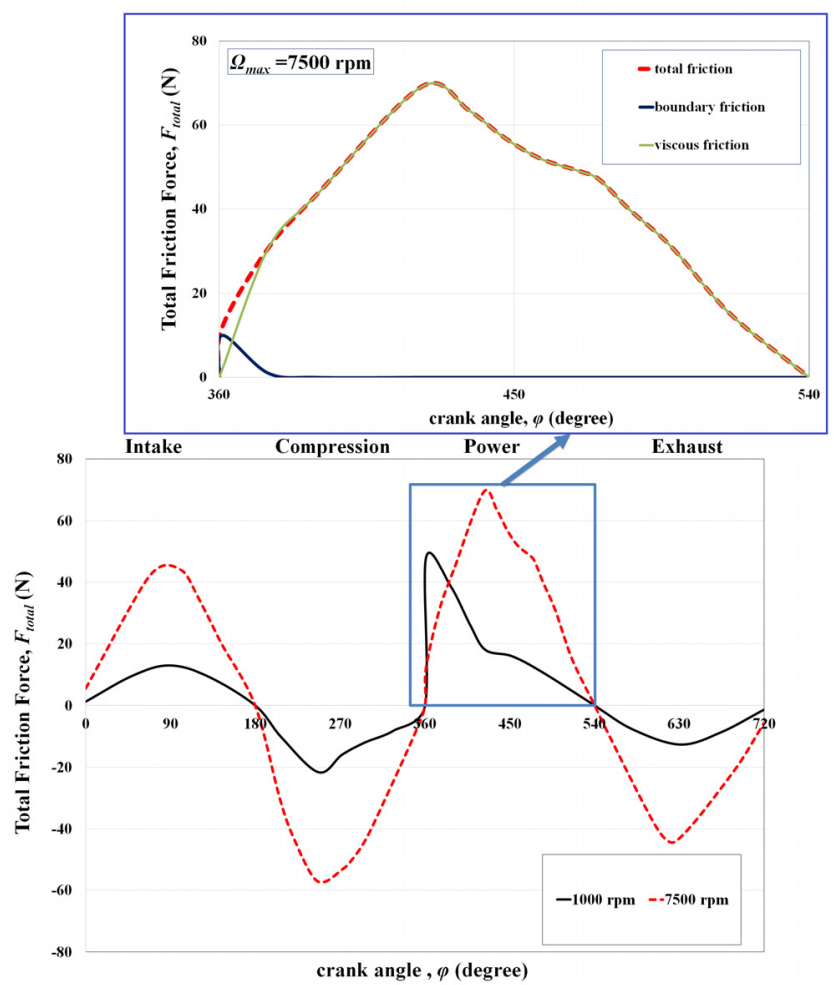

Fig. 16. Computed total friction force versus crank angle at idle and maximum rotational crankshaft speeds.

which is in line with the expression of the viscous shear stress and lubricant film thickness. As observed in Figure 16, the total friction increased from $19.8 \mathrm{~N}$ to $67.6 \mathrm{~N}$ at the mid-stroke position under the power conditions, and the piston linear velocity increased from $2.61 \mathrm{~m} . \mathrm{s}^{-1}$ to $19.62 \mathrm{~m} \cdot \mathrm{s}^{-1}$. The total power loss follows the same behaviour as the total friction variation. The inclusion of piston speed increment leads to a significant portion of frictional power losses. In "ZOOM A" area, the total power losses at the speed of $1000 \mathrm{rpm}$ under power engine state are illustrated. The power losses increased substantially from $50.2 \mathrm{~W}$ to $1290 \mathrm{~W}$ as the rotational crankshaft speed increased.

\subsection{Variation of curvature profile}

To investigate how much the curvature profile of the top compression ring influences the engine tribological performance, the assumption of a higher curvature design is examined under the same operating engine conditions. As follows from Figure 18, comparison between a top ring with lower curvature height $C=3 \mu \mathrm{m}$ (reference case) and a top ring with higher curvature profile $C=15 \mu \mathrm{m}$ (examined case) is illustrated. In this simulation, the effects of the compression ring curvature profile are clearly addressed at low rotational speed, which is in agreement with the stop-start driving of typical motorbike use.

Figure 19 illustrates the hydrodynamic pressure profiles along the compression ring axial width at idle speed 

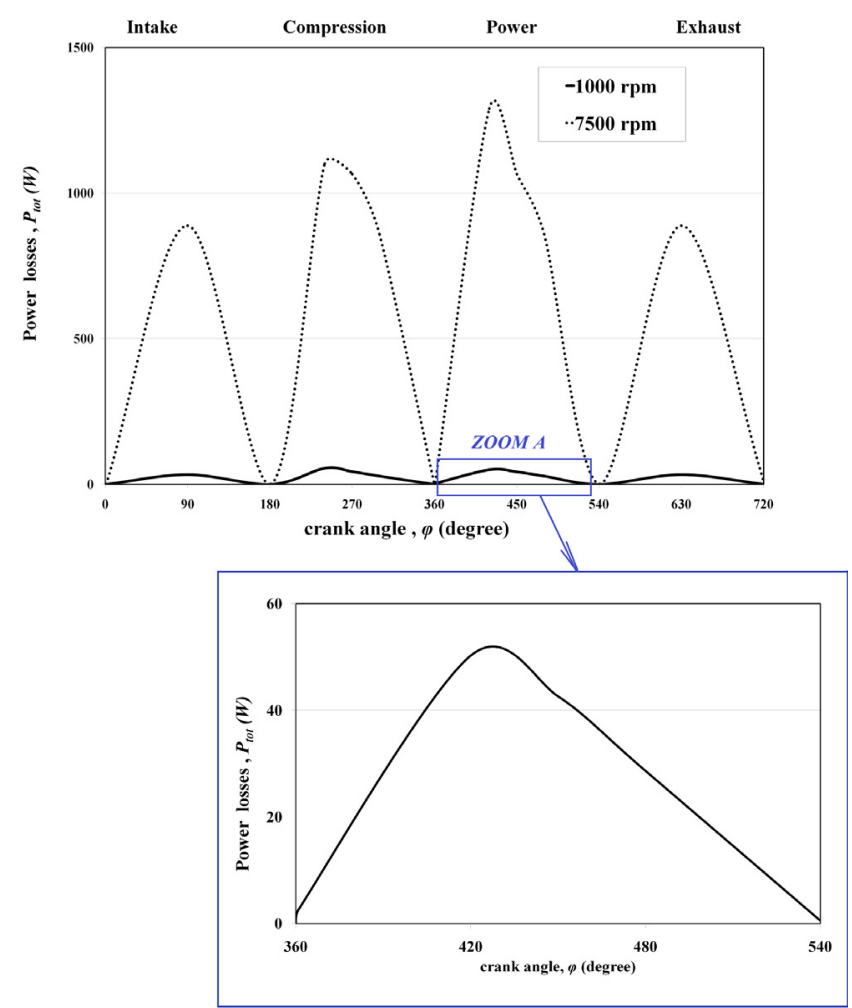

Fig. 17. Computed total power losses versus crank angle at idle and maximum rotational crankshaft speeds.

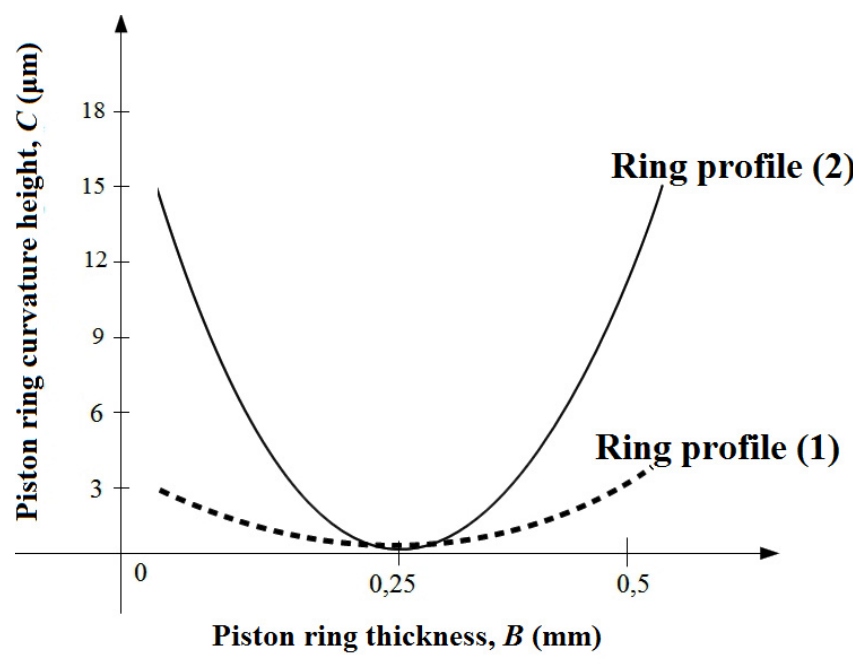

Fig. 18. Comparison between different compression ring curvature profiles.

$\Omega_{\text {idle }}=1000 \mathrm{rpm}$ for various ring curvature profiles. When the height of the ring curvature varies from $3 \mu \mathrm{m}$ to $15 \mu \mathrm{m}$, a significant change in the percentage of hydrodynamic support is observed. The computed maximum pressure is enhanced at the centre of the ring thickness as the curvature height increases. These numerical results are obtained as the top ring is moved upward at the TDC $\left(\varphi=359^{\circ}\right)$. In detail, a larger curvature profile ensures thinner lubricant films, which can increase the generated

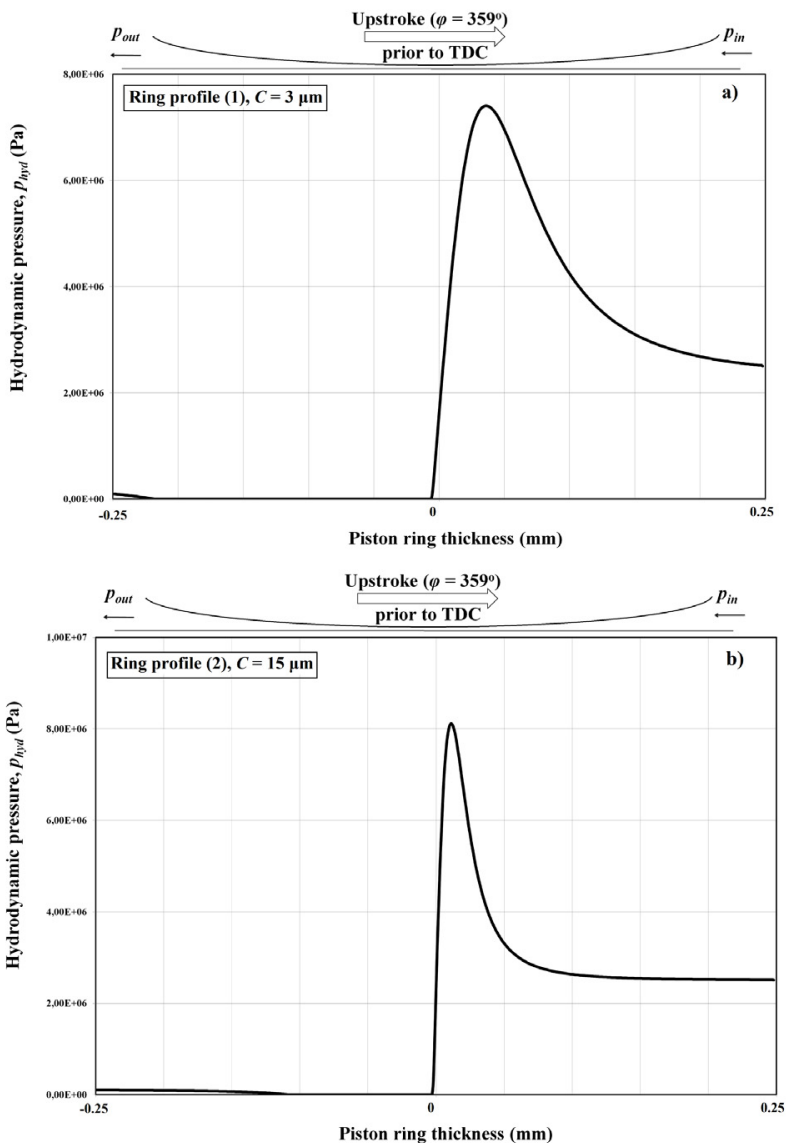

Fig. 19. Effect of curvature profile on pressure profile prior to $\operatorname{TDC}\left(\varphi=359^{\circ}\right.$ at compression to power stage) under idle rotational speed.

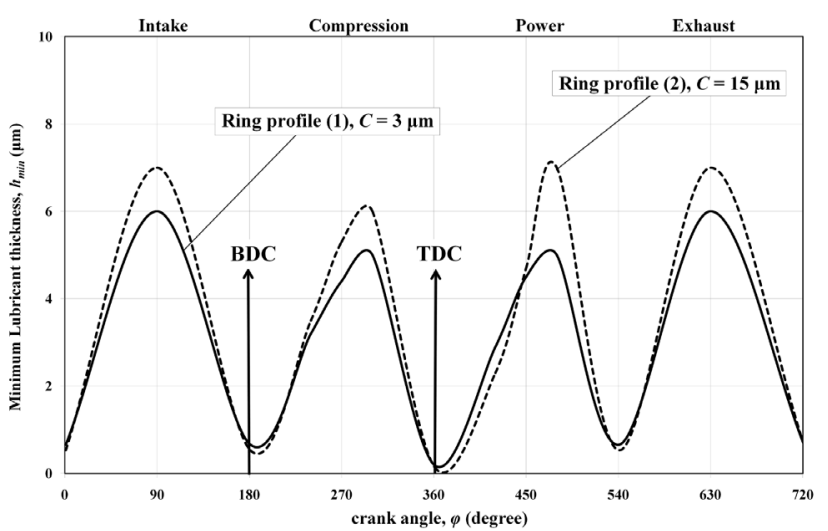

Fig. 20. Effect of curvature profile on the minimum lubricant thickness at idle rotational speed.

pressure gradient. On the other hand, when the height of ring curvature is $3 \mu \mathrm{m}$, the "flatter" ring geometry encourages a slightly better wedge effect, thus marginally improving the minimum film thickness at piston reversal, especially at the TDC. The lubricant film variation for this engine investigation is shown in Figure 20. Lower curvature heights of the ring profile promote minimum 


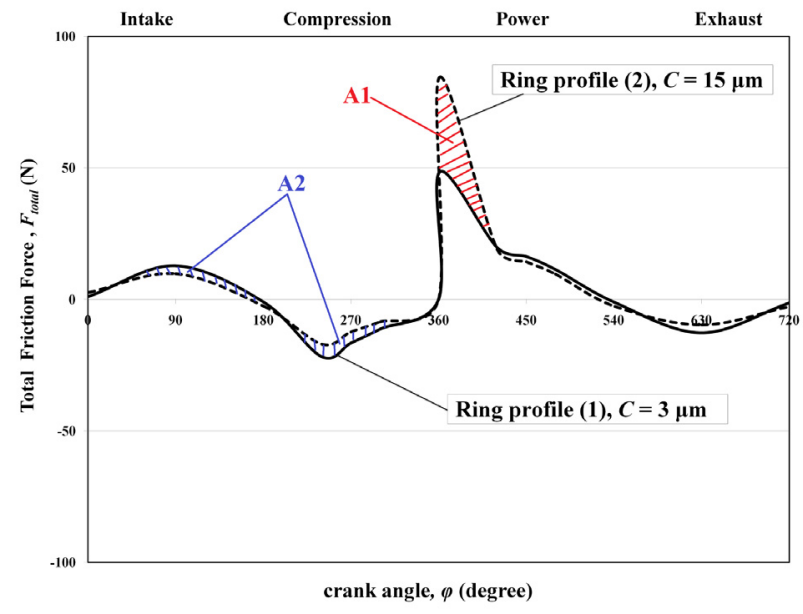

Fig. 21. Effect of curvature profile on total friction force at idle rotational speed.

film thickness around the boundary/mixed conditions. In particular, the lower shape of curvature increases the film thickness and load carrying capacity for a slow piston linear velocity, and then the contact load of the asperities substantially decreases. The minimum lubricant film varies between $0.28 \mu \mathrm{m}$ to $0.405 \mu \mathrm{m}$ for smaller curvature heights, whereas for the higher curvature heights, the values vary between $0.1 \mu \mathrm{m}$ to $0.31 \mu \mathrm{m}$ for the certain engine running conditions. On the other hand, as the engine speed is increased, thicker films are obtained for higher curvature profiles during the middle of each stroke. This effect is realistic due to the increment of a wedge effect as the lubricant flows into the ring-cylinder clearance. As the height of the ring curvature increases, the shape of the ring surface pronounces the ring-bore gap, giving a thicker film and a correspondingly slighter viscous friction. For instance, at the power stroke, the minimum film thickness is approximately $5 \mu \mathrm{m}$ to $6 \mu \mathrm{m}$ for the smaller heights of the ring profile curve, whereas for higher curve heights, the values have been considered approximately $6 \mu \mathrm{m}$ to $7 \mu \mathrm{m}$.

Figures 21 and 22 show a comparison of the total and boundary friction for the cases of lower and high curve top compression ring profiles, corresponding to lower rotational speed of $1000 \mathrm{rpm}$. As expected, at the TDC area, the higher heights of the curvature profile had a significantly insufficient minimum film thickness due to the increment of the boundary friction because the prevailing regime of lubrication is boundary/mixed. Thus, "flatter" rings can improve the friction force, which is in line with other published reports $[3,4,7,12]$ relative to the compression ring profile design. The variation of the average total friction for the two examined profiles (low curvature $C=3 \mu \mathrm{m}$ and high curvature $C=15 \mu \mathrm{m})$ is presented in Figure 21. Two regions can be created to evaluate the relative differences. One (A1) is the average variation in the total friction force predicted by the two ring profiles in the vicinity of the power stroke TDC $\left(360^{\circ}\right.$ and $400^{\circ}$ of crank angle). When the height of the ring curvature is

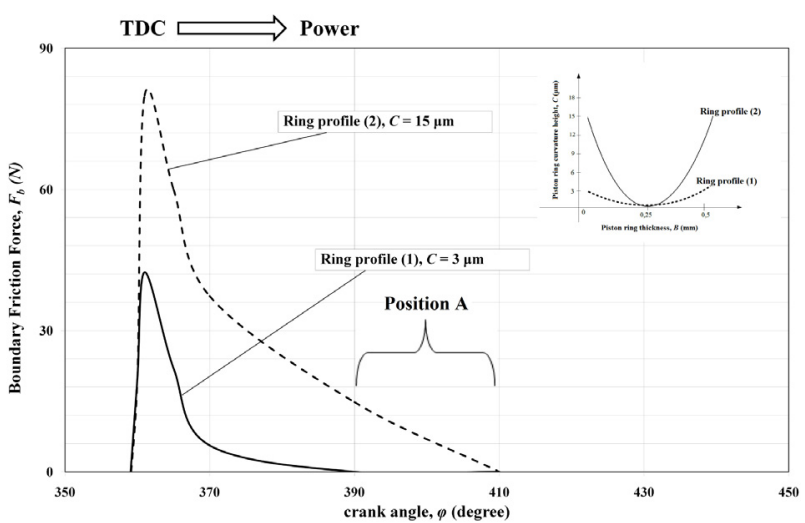

Fig. 22. Curvature profile effect on boundary friction at TDC region for idle rotational speed.

$15 \mu \mathrm{m}$, the average absolute total friction increases $38.3 \%$ compared to the lower curvature height $C=3 \mu \mathrm{m}$. The boundary interactions in this case are dominant. Regarding the second region (A2), it is evident that higher curvature profile decreases the average total friction $22.4 \%$ in the middle of each stroke compared to the reference case.

With extremely thin lubricant film at the TDC and $\mathrm{BDC}$, the compression ring is imposed in the mixed lubrication or boundary lubrication. Thus, the boundary friction accounts for a large proportion of the total friction. As shown in Figure 22, it is important to note that the part of the mixed lubrication is the lowest for the case of lower curvature profile. At this point, the inset to the figure (see Position A) shows the variation of the boundary/mixed lubrication regime in the aforementioned region. Therefore, a "flatter" ring shape should result in lower asperity friction and better sealing and consumption performance. The maximum boundary friction, for instance, increased $47 \%$ when using a higher curve top compression ring than a lower profiled ring. As follows from Table 4, the predicted power losses were significantly enhanced at TDC reversal and minimized at the piston mid-position during the low speed driving of this motorbike engine.

Finally, these observations should be compared for in-plane dynamics and fully transient cases for the compression ring-cylinder conjunction. The presented methodology does not include comparable results; hence, the current computational work needs to proceed further. However, this paper provides a promising method to solve the compression ring-cylinder lubrication problem, with the solution time of simulation to be less than $1 \mathrm{~h}$ minimum for a full engine cycle.

\section{Concluding Remarks and Future Outlook}

In the current paper, a tribological model of the top compression ring has been presented. A 2D CFD axisymmetric model is built to solve the Navier-Stokes equations 
A. Zavos and P.G. Nikolakopoulos: Mechanics \& Industry 18, 208 (2017)

Table 4. Predicted total power losses under different curvature profiles at idle rotational speed for various crank angles.

\begin{tabular}{ccc}
\hline Curvature height & Boundary friction (N) & Total power losses (W) \\
\hline$C=3 \mu \mathrm{m} @ 359^{\circ}$ & 42.4 & 2.75 \\
$C=3 \mu \mathrm{m} @ 365^{\circ}$ & 22 & 10.29 \\
$C=3 \mu \mathrm{m} @ 420^{\circ}$ & 0 & 50.24 \\
$C=3 \mu \mathrm{m} @ 450^{\circ}$ & 0 & 42.62 \\
$C=15 \mu \mathrm{m} @ 359^{\circ}$ & 80 & 4.81 \\
$C=15 \mu \mathrm{m} @ 365^{\circ}$ & 60 & 20.09 \\
$C=15 \mu \mathrm{m} @ 420^{\circ}$ & 0 & 48.51 \\
$C=15 \mu \mathrm{m} @ 450^{\circ}$ & 0 & 37.21 \\
\hline
\end{tabular}

by considering in-plane equilibrium. The basic geometry of the compression ring-cylinder system is obtained from a real four stoke gasoline motorbike engine. The current analysis simulates the in-plane ring boundary/mixed isothermal lubrication response in a quasi-static manner. The asperity interactions and the rheological parameters variation along the ring axial width are taken into account. The computed results are also verified against other numerical and experimental results in the literature, showing a sensible agreement.

The influence of the engine speed and the curvature shape of the ring profile has been investigated with respect to the top ring tribological performance. At lower engine speeds, the availability of the minimum film thickness is limited, forming a high boundary friction at piston reversal. In contrast, as the engine speed is increased, full-hydrodynamic lubrication to the compression ringcylinder conjunction is obtained, with thicker lubricant films. Therefore, the total frictional losses increase due to increased shear stress and viscous friction during the middle of each stroke.

In addition, the curvature shape of the ring profile must be examined to obtain an optimum geometrical profile, which leads to a better tribological behaviour. Two types of curvatures have been described and compared, taking into account the minimum film thickness, the total friction and the total power losses. The results were obtained at low rotational speeds. In practice, the "flatter" ring profiles, having a larger minimum lubricant film at piston reversals, show marginal total friction and losses. In the case of higher curvatures, the compression ring has high asperity friction at the TDC and the boundary/mixed lubrication is promoted. Furthermore, the higher height curve of the top compression ring design improves the lubricant film at the middle of the strokes, and the wedge effect is more dominant in the ring-cylinder clearance. However, as the height of the ring curvature increases, thicker films are formed, leading to an increased fuel consumption.

The present simulation model shows that more work is needed to optimize the curvature shape of the top compression ring. Bore out of roundness, ring face profile and the roughness of the ring and liner surfaces are very important parameters in the ring-liner and ring-groove cooperation. The ring motion with elastic deformations in the piston groove has a dominant influence on the engine operation. Thus, an elasto-dynamic model would provide a more complete analysis for the operating conditions of interest. Finally, the effect of the cavitation zone along the ring thickness under different curvature profiles must also be examined.

Acknowledgements. This work was supported by Grant E.039 from the Research Committee of the University of Patras (Programme K. Karatheodori).

\section{References}

[1] D.E. Richardson, Review of power cylinder friction for diesel engines, J. Eng. Gas Turbines Power 122 (2000) 506-519

[2] M. Priest, C.M. Taylor, Automobile Engine Tribology: Approaching the Surface, Wear 241 (2000) 193-203

[3] M. Priest, D. Dowson, C.M. Taylor, Predictive wear modelling of lubricated piston rings in a diesel engine, Wear 231 (1999) 89-101

[4] Y.-R. Jeng, Theoretical analysis of piston-ring lubrication Part 1-fully flooded lubrication, Tribol. Trans. 35 (1992) 696-706

[5] Y.-R. Jeng, Theoretical analysis of piston-ring lubrication, Part II - starved lubrication and its application to a complete ring pack, Tribol. Trans. 35 (1992) 707-714

[6] P.S. Dellis, Effect of friction force between piston rings and liner: a parametric study of speed, load, temperature, piston-ring curvature, and high-temperature, high-shear viscosity, Proc. Inst. Mech. Eng. J: J. Eng. Tribol. 224 (2010) 411-426

[7] R.I. Taylor, Squeeze film lubrication in piston rings and reciprocating contacts, Proc. Inst. Mech. Eng. J: J. Eng. Tribol. (2015), DOI: 1350650114564234

[8] O. Akalin, G.M. Newaz, Piston ring-cylinder bore friction modeling in mixed lubrication regime: part I - analytical results, J. Tribol. 123 (1999) 211-218

[9] P.C. Mishra, H. Rahnejat, P.D. King, Tribology of the ring-bore conjunction subject to a mixed regime of lubrication, Proc. Inst. Mech. Eng. C: J. Mech. Eng. Sci. 223 (2009) 987-998

[10] P.C. Mishra, S. Balakrishnan, H. Rahnejat, Tribology of compression ring-to-cylinder contact at reversal, Proc. Inst. Mech. Eng. J: J. Eng. Tribol. 222 (2008) 815-826

[11] S. Furuhama, S. Sasaki, New device for the measurement of piston frictional forces in small engines, Soc. Automotive Eng. Paper No. 8312841983 
[12] N. Morris, R. Rahmani, H. Rahnejat, P.D. King, B. Fitzsimons, The influence of piston ring geometry and topography on friction, Proc. Inst. Mech. Eng. J: J. Eng. Tribol. 227 (2013) 141-153

[13] N. Morris, R. Rahmani, H. Rahnejat, P.D. King, B. Fitzsimons, Tribology of piston compression ring conjunction under transient thermal mixed regime of lubrication, Tribol. Int. 59 (2013) 248-258

[14] N. Patir, H.S. Cheng, An average flow model for determining effects of three-dimensional roughness on partial hydrodynamic lubrication, Trans. ASME Ser. F J. Lubr. Technol. 100 (1978) 12-17

[15] G. Styles, R. Rahmani, H. Rahnejat, B. Fitzsimons, Incycle and life-time friction transience in piston ring-liner conjunction under mixed regime of lubrication, Int. J. Engine Res. 15 (2014) 862-876

[16] Y. Guo, X. Lu, W. Li, T. He, D. Zou, A mixed-lubrication model considering elastoplastic contact for a piston ring and application to a ring pack, Proc. Inst. Mech. Eng. D: J. Automobile Eng. 229 (2015) 174-188

[17] J.A. Greenwood, J.H. Tripp, The contact of two nominally flat rough surfaces, Proc. Inst. Mech. Eng. 185 (1970) 48-71

[18] A. Sonthalia, C.R. Kumar, The effect of compression ring profile on the friction force in an internal combustion engine, Tribol. Ind. 35 (2013) 74-83

[19] Y. Hu, H.S. Cheng, T. Arai, Y. Kobayashi, S. Aoyama, Numerical simulation of piston ring in mixed lubrication a nonaxisymmetrical analysis, J. Tribol. 116 (1994) 470478

[20] T. Hamatake, T. Kitahara, Y. Wakuri, M. Soejima, Friction characteristics of piston rings in a reciprocating engine, Lubrication Sci. 6 (1993) 21-40

[21] H. Shahmohamadi, R. Rahmani, H. Rahnejat, C.P. Garner, P.D. King, Thermo-mixed hydrodynamics of piston compression ring conjunction, Tribol. Lett. 51 (2013) $323-340$
[22] H. Shahmohamadi, R. Rahmani, H. Rahnejat, C.P. Garner, CFD modelling of cavitation phenomenon in piston ring/cylinder liner conjunction, Proceedings of 5th World Tribology Congress (WTC 2013), Torino, Italy, 2013, p. 4

[23] A. Zavos, P. Nikolakopoulos, Effects of surface irregularities on piston ring-cylinder tribo pair of a two stroke motor engine in hydrodynamic lubrication, Tribol. Int. 37 (2015) 1-12

[24] A. Zavos, P.G. Nikolakopoulos, Effects of monograde and multigrade oils on the friction force in four-stroke motor engine: an experimental and analytical approach, In: Vibration Engineering and Technology of Machinery, Springer International Publishing, 2015, Vol. 23, pp. 507517

[25] A. Zavos, P.G. Nikolakopoulos: A tribological study of piston rings lubricated by power law oils, Proc. Inst. Mech. Eng. J: J. Eng. Tribol. (2015) DOI: $10.1177 / 1350650115606481$

[26] C.L. Felter, Numerical simulation of piston ring lubrication, Tribol. Int. 41 (2008) 914-919

[27] R. Richard, Introduction to Internal Combustion Engines, 3rd edition, Macmilan Press Ltd, 1999

[28] F.M. White, Viscous Fluid Flow, 2nd edition, McGrawHill, 1991

[29] D. Dowson, G.R. Higginson, A numerical solution to the elasto-hydrodynamic problem, J. Mech. Eng. Sci. 1 (1959) 6-15

[30] C.J.A. Roelands, Correlational aspects of the viscositytemperature-pressure relationship of lubricating oils, Ph.D. thesis, Technical University Delft, Delft, The Netherlands, 1966

[31] L. Houpert, New results of traction force calculations in elastohydrodynamic contacts, ASME J. Trib. T 107 (1985) 241-248 